\title{
Incidence of depression in relation to transportation noise exposure and noise annoyance in the SAPALDIA study
}

\author{
Ikenna C. Eze ${ }^{\mathrm{a}, \mathrm{b}, *}$, Maria Foraster ${ }^{\mathrm{a}, \mathrm{b}, \mathrm{c}, \mathrm{d}, \mathrm{e}}$, Emmanuel Schaffner ${ }^{\mathrm{a}, \mathrm{b}}$, Danielle Vienneau ${ }^{\mathrm{a}, \mathrm{b}}$, \\ Reto Pieren ${ }^{\mathrm{f}}$, Medea Imboden ${ }^{\mathrm{a}, \mathrm{b}}$, Jean-Marc Wunderli ${ }^{\mathrm{f}}$, Christian Cajochen ${ }^{\mathrm{g}, \mathrm{h}}$, Mark Brink ${ }^{\mathrm{i}}$, \\ Martin Röösli ${ }^{\mathrm{a}, \mathrm{b}}$, Nicole Probst-Hensch ${ }^{\mathrm{a}, \mathrm{b}}$ \\ ${ }^{a}$ Swiss Tropical and Public Health Institute, Basel, Switzerland \\ ${ }^{\mathrm{b}}$ University of Basel, Basel, Switzerland \\ ${ }^{\mathrm{c}}$ ISGlobal, Barcelona Institute for Global Health, University Pompeu Fabra, Barcelona, Spain \\ ${ }^{\mathrm{d}}$ CIBER Epidemiologia y Salud Publica, Madrid, Spain \\ ${ }^{\mathrm{e}}$ Blanquerna School of Health Science, Universitat Ramon Llull, Barcelona, Spain \\ ${ }_{\mathrm{f}}^{\mathrm{f}}$ Empa, Laboratory for Acoustics/Noise Control, Swiss Federal Laboratories for Material Science and Technology, Dübendorf, Switzerland \\ ${ }^{\mathrm{g}}$ Center for Chronobiology, Psychiatric Hospital of the University of Basel, Basel, Switzerland \\ ${ }^{\mathrm{h}}$ Transfaculty Research Platform Molecular and Cognitive Neurosciences, University of Basel, Basel, Switzerland \\ ${ }^{\mathrm{i}}$ Federal Office for the Environment, Bern, Switzerland
}

\section{A R T I C L E I N F O}

Handling Editor: Hanna Boogaard

\section{Keywords:}

Noise

Transportation

Aircraft

Railway

Road traffic

Annoyance

Depression

Mental health

Air pollution

Prospective studies

\begin{abstract}
A B S T R A C T
Prospective evidence on the risk of depression in relation to transportation noise exposure and noise annoyance is limited and mixed. We aimed to investigate the associations of long-term exposure to source-specific transportation noise and noise annoyance with incidence of depression in the SAPALDIA (Swiss cohort study on air pollution and lung and heart diseases in adults) cohort.

We investigated 4,581 SAPALDIA participants without depression in the year 2001/2002. Corresponding oneyear mean road, railway and aircraft day-evening-night noise (Lden) was calculated at the most exposed façade of the participants' residential floors, and transportation noise annoyance was assessed on an 11-point scale. Incident cases of depression were identified in 2010/2011, and comprised participants reporting physician diagnosis, intake of antidepressant medication or having a short form-36 mental health score $<50$. We used robust Poisson regressions to estimate the mutually adjusted relative risks (RR) and 95\% confidence intervals (CI) of depression, independent of traffic-related air pollution and other potential confounders.

Incidence of depression was 11 cases per 1,000 person-years. In single exposure models, we observed positive but in part, statistically non-significant associations (per $10 \mathrm{~dB}$ ) of road traffic Lden [RR: $1.06(0.93,1.22)]$ and aircraft Lden [RR: $1.19(0.93,1.53)]$, and (per 1-point difference) of noise annoyance [RR: $1.05(1.02,1.08)$ ] with depression risk. In multi-exposure model, noise annoyance effect remained unchanged, with weaker effects of road traffic Lden [(RR: $1.02(0.89,1.17)]$ and aircraft Lden [(RR: $1.17(0.90,1.50)]$. However, there were statistically significant indirect effects of road traffic Lden $[(\beta: 0.02(0.01,0.03)]$ and aircraft Lden $[\beta: 0.01$ (0.002, 0.02)] via noise annoyance. There were no associations with railway Lden in the single and multiexposure models $\left[\left(\mathrm{RR}_{\mathrm{both}}\right.\right.$ models: $\left.0.88(0.75,1.03)\right]$. We made similar findings among 2,885 non-movers, where the effect modification and cumulative risks were more distinct. Noise annoyance effect in non-movers was stronger among the insufficiently active (RR: $1.09 ; 95 \%$ CI: $1.02,1.17 ; p_{\text {interaction }}=0.07$ ) and those with daytime sleepiness [RR: 1.07 (1.02, 1.12); $p_{\text {interaction }}=0.008$ ]. Cumulative risks of Lden in non-movers showed additive tendencies for the linear cumulative risk $\left[\left(\mathrm{RR}_{\mathrm{per}} 10 \mathrm{~dB}\right.\right.$ of combined sources: $\left.1.31(0.90,1.91)\right]$ and the categorical cumulative risk $\left[\left(\mathrm{RR}_{\text {triple- vs. zero-source } \geq 45 \mathrm{~dB}}: 2.29(1.02,5.14)\right]\right.$, and remained stable to noise annoyance.

Transportation noise level and noise annoyance may jointly and independently influence the risk of depression. Combined long-term exposures to noise level seems to be most detrimental, largely acting via annoyance. The moderation of noise annoyance effect by daytime sleepiness and physical activity further
\end{abstract}

Abbreviations: BMI, Body mass index; BDNF, Brain-derived neurotropic factor; CI, Confidence interval; CVD, Cardiovascular disease; GSEM, Generalized structural equation model; Lden, Day-evening-night noise level; $\mathrm{NO}_{2}$, Nitrogen dioxide; RR, Relative risk; SAPALDIA, Swiss cohort study on air pollution and lung and heart diseases in adults; SAP2, Second wave of the SAPALDIA study; SAP3, Third wave of the SAPALDIA study; SEP, Socio-economic position

* Corresponding author at: Department of Epidemiology and Public Health, Swiss Tropical and Public Health Institute, Socinstrasse 57, 4051 Basel, Switzerland.

E-mail address: ikenna.eze@swisstph.ch (I.C. Eze). 
contribute to clarifying the involved mechanisms. More evidence is needed to confirm these findings for effective public health control of depression and noise exposure burden.

\section{Introduction}

Depression ranks high among the risk factors for global disease burden (Vos et al., 2016). Its worldwide prevalence is increasing and is currently the leading contributor to years lived with disability (WHO, 2017). The burden of depression is enormous given its high rate of relapse, even after successful treatment (Hardeveld et al., 2010; Lépine and Briley, 2011). Depression is a frequent comorbidity of chronic diseases (Voinov et al., 2013) and is associated with physical (Druss et al., 2009; Judd et al., 2000) and social role dysfunction (Briley and Moret, 2010; Rotermann, 2007) as well as all-cause mortality (Bostwick and Pankratz, 2000; Osby et al., 2001).

Depression and mental health in general have a complex etiology that involves genetic, environmental and social factors. The environmental determinants of depression have received attention in recent years, with air pollutants having the largest evidence (Fan et al., 2020; van den Bosch and Meyer-Lindenberg, 2019). Air pollutants are thought to act through alterations in neurotransmitter activity (Barragán-Mejía et al., 2002; González-Piña and Paz, 1997), and neural plasticity (Bos et al., 2011), as well as inflammation and oxidative stress in brain sites that may include prefrontal cortex and striatum (Dorado-Martínez et al., 2001; Meng et al., 2003). Transportation noise-a frequent correlate of traffic-related air pollution, which together constitute the greatest contribution to environmental disease burden-is thought to contribute to the burden of depression by inducing annoyance, and stress, and by its sleep disturbing properties (Babisch, 2003; Babisch et al., 2013; Persson-Waye et al., 2002; Slavich and Irwin, 2014). Acute exposure to high road traffic noise levels induced DNA methylation changes in the $B D N F$ (brain-derived neurotrophic factor) gene in specific brain regions in animal models (Guo et al., 2017). Reduced BDNF expression and serum BDNF levels were frequently associated with depression in human studies (Bus et al., 2015; Cattaneo et al., 2016). Differential methylation at TRIM39 gene, which is involved in inflammatory response (Roberts Jr et al., 2007; Zhang et al., 2012), was recently linked to depression (Crawford et al., 2018; Zhu et al., 2019) and to traffic-related noise and air pollution (Eze et al., 2020). While transportation noise level is a relevant risk factor to consider, subjective noise annoyance (reflecting inter-individual variability in noise perception) might better capture certain health effects of noise exposure as demonstrated by recent studies (Eze et al., 2018; Foraster et al., 2016; Martens et al., 2018). Noise annoyance may trigger negative emotions and activate stress responses in the Hypothalamic-Pituitary-Adrenal (HPA) axis, which is involved in the pathophysiology of depression (Keller et al., 2017; Slavich and Irwin, 2014). Poor sleep resulting from noise-induced sleep disturbances also relates to the occurrence of depression (Halperin, 2014; Sygna et al., 2014; Tsuno et al., 2005).

There is suggestive but mixed epidemiological evidence linking transportation noise and depression. Exposure to aircraft noise was associated with depressive symptoms (Hiramatsu et al., 1997) but lack of association was also reported (Baudin et al., 2018; Tarnopolsky et al., 1980; Wright et al., 2018). For road traffic noise, a positive association was reported for incidence of depressive symptoms (Orban et al., 2015), and prevalent depression or antidepressant use (Krefis et al., 2017; Leijssen et al., 2019; Seidler et al., 2017; Yoshida et al., 1997), but weak or no associations were also observed (Okokon et al., 2018; Stansfeld et al., 1996; Sygna et al., 2014). Pooled estimates revealed a weak positive association of road traffic noise and depression (Dzhambov and Lercher, 2019). So far, two studies investigating railway noise have reported a positive association with prevalent depression or psychological distress (Klompmaker et al., 2019; Seidler et al., 2017). Noise annoyance or sensitivity on the other hand, were more consistently associated with depression. Environmental noise annoyance (Beutel et al., 2016; Dratva et al., 2010; Hammersen et al., 2016; Jensen et al., 2018; Rocha et al., 2012; Yoon et al., 2014) and noise sensitivity (Kishikawa et al., 2009; Okokon et al., 2018; Park et al., 2017; Stansfeld and Shipley, 2015; Stansfeld, 1992) were positively associated with poor mental health, depression or antidepressant use. Annoyance from aircraft noise was also linked with depression (Baudin et al., 2018; Schreckenberg et al., 2010).

Few previous studies on transportation noise or noise annoyance (in relation to depression in a general population) had a longitudinal design (Orban et al., 2015; Stansfeld et al., 1996), considered all three major transportation noise sources (Klompmaker et al., 2019; Seidler et al., 2017), explored noise level and annoyance (Baudin et al., 2018; Okokon et al., 2018), or included the potentially confounding effect of traffic-related air pollution (Klompmaker et al., 2019). Furthermore, evidence on potential pathways mediating the effect of noise exposure on depression are limited, despite the plausibility of mediation by noise annoyance and behavioral factors that might be in the etiologic pathway linking noise exposure to mental health (Dzhambov et al., 2017; Dzhambov et al., 2018; Kroesen et al., 2008).

In light of the above evidence and research needs, we aimed primarily, to investigate the mutually independent associations of longterm exposure to road traffic, aircraft and railway noise and transportation noise annoyance with incidence of depression, independent of traffic-related air pollution and other potential confounders. We also aimed secondarily, to test the mediation of the noise level associations by noise annoyance and other potential mediators in the SAPALDIA (Swiss cohort study on air pollution and lung and heart diseases in adults) cohort.

\section{Methods}

\subsection{Study population}

We carried out this study within the Swiss Cohort Study on Air Pollution and Lung and Heart Diseases in Adults (SAPALDIA) which began in 1991 (SAP1) with 9651 randomly-selected participants from eight Swiss areas. First follow-up (SAP2) occurred in 2001/2002 and included 8047 participants, whereas second follow-up occurred in 2010/2011 and included 6088 participants. SAP1 focused on air pollution and respiratory health whereas SAP2 and SAP3 expanded into cardio-metabolic outcomes and wellbeing, and included the establishment of the SAPALDIA $-80{ }^{\circ} \mathrm{C}$ biobank. In each survey, participants underwent health examination and provided questionnaire data covering their lifestyle and health status. Details of the SAPALDIA study protocols are provided elsewhere (Ackermann-Liebrich et al., 2005; Martin et al., 1997).

Inclusion criteria for the present study were: (i) participation at SAP2 and SAP3, (ii) having no depression at SAP2 and (iii) having complete data on source-specific transportation noise level, noise annoyance and relevant covariates at SAP2, that enable the assessment of the link between these exposures at SAP2 and incidence of depression between SAP2 and SAP3. The present study therefore included 4,581 participants who participated at both SAP2 and SAP3, were free of depression at SAP2 and had complete relevant data to achieve the objectives of this study. Fig. S1 presents the details of participant selection for the present study. Ethical approvals for the SAPALDIA studies were obtained from Ethics committees of North-West Switzerland, and the Swiss Academy of Medical Sciences. All participants provided informed 
written consent before participating in any aspect of the SAPALDIA studies.

\subsection{Incidence of depression}

At SAP2 and SAP3, participants responded to questions on having doctor-diagnosed depression or use of antidepressants. Participants also completed the short-form 36 mental health domain questionnaire, which was aggregated into a mental component summary score, derived according to developer-specified algorithms and standardized to a mean of 50 and standard deviation of 10, with higher scores representing better mental health (Ware and Kosinski, 2001). The mental health score was recently shown to have good validity in identifying cases of depression in epidemiological settings, at a cut-off level of 50 (Kiely and Butterworth, 2015; Silveira et al., 2005). We therefore defined composite incident depression at SAP3 as the absence of doctordiagnosed depression and intake of antidepressants, and mental health score $\geq 50$ at SAP2, and the presence of doctor-diagnosed depression or intake of antidepressants or mental health score $<50$ at SAP3.

\subsection{Transportation noise exposure}

In the framework of the Short- and Long-term Effects of Transportation Noise Exposure (SiRENE) project (Röösli et al., 2017), annual day-evening-night road traffic, railway and aircraft noise (Lden) were calculated for 2001 (SAP2) and 2011 (SAP3) using validated Swiss noise calculation models at the most exposed façade point of participants' dwelling unit as described (Karipidis et al., 2014). Input data for the road traffic noise modelling included the road network, hourly traffic statistics, speed limit, bridges, and noise barriers. Aircraft noise calculations covered four Swiss airports in Zurich, Basel, Geneva and Payerne with input data such as air traffic statistics, radar tracks or idealized flight paths. Input data for railway noise calculations included train types, speeds, railway traffic statistics, geometry of railway tracks, and noise barriers. Following noise calculation, participants without substantial noise exposures were assigned truncated Lden values of $30 \mathrm{~dB}$ for aircraft and railway noise and $35 \mathrm{~dB}$ for road traffic noise (Karipidis et al., 2014). Model validation studies comparing the measured and calculated values showed good consistency, with a combined Lden difference of $1.6 \pm 5 \mathrm{~dB}$ (Schlatter et al., 2017). Source-specific Ldens at SAP2 and SAP3 were correlated (Spearman $r_{\text {road traffic }}=0.70$, $r_{\text {aircraft }}=0.67$ and $r_{\text {railway }}=0.76$ ). We derived the absolute change in source-specific Lden (SAP3 - SAP2), for sensitivity analysis.

To explore more complex and cumulative exposure situations, we created a source-specific binary "exposed" variable where participants were designated as exposed if their source-specific noise exposure was $\geq 45 \mathrm{~dB}$ (Heritier et al., 2017; Pyko et al., 2019). Based on this, we created a combined categorical variable ("zero-source", "single-source", "double-source" and "triple-source" exposure) for further analysis similar to recent studies (Pyko et al., 2019; Pyko et al., 2017).

\subsection{Transportation noise annoyance}

Noise annoyance at SAP2 and SAP3 were assessed as part of the health interview, as previously described (Eze et al., 2018; Foraster et al., 2016). Participants responded to the question, "How much are you annoyed by noise from transportation noise at home when the windows are opened?" The responses had a 0-10 rating similar to the validated numerical 11-point noise annoyance scale (Fields et al., 2001). Noise annoyance at SAP2 and SAP3 were moderately correlated $(r=0.43)$. We also derived absolute change in noise annoyance score (SAP3 - SAP2), for sensitivity analysis.

\subsection{Relevant covariates}

We considered the following potential confounders at SAP2-that might be antecedent to, or associated with noise and depression, but not in the causal pathway-for inclusion in the present study: age (years), sex (male/female), educational attainment ( $\leq 9$ years compulsory education/10-13 years corresponding to secondary education or apprenticeship/ > 13 years corresponding to tertiary education). We also included participants' study area (Basel/Wald/Davos/Lugano/ Montana/Payerne/Aarau/Geneva), and neighborhood socio-economic position (SEP; an index (\%) calculated as principal component analysis of education and financial attributes of household in a neighborhood derived from the 2001 Census (Panczak et al., 2012)). These covariates capture the socio-demographic and socio-economic attributes, which could confound noise-depression association (Dreger et al., 2019; Lund et al., 2018).

We also considered at SAP2, potentially competing risk factors (or modifiers) — that might be antecedent to depression, but not necessarily to noise-for higher precision of estimates without bias (Pearl et al., 2016). These included smoking status (Fluharty et al., 2017), alcohol consumption (Gea et al., 2013), fruit and vegetable intake (Saghafian et al., 2018), family history of depression (Weissman et al., 2005), residential greenness (Banay et al., 2019; Bratman et al., 2019) and traffic-related air pollution (Antonsen et al., 2020; van den Bosch and Meyer-Lindenberg, 2019). We defined smoking status of participants as never, former or current smoker, and defined as alcohol consumption as having $\leq 1 />1$ glass per day. We also defined fruit and vegetable intake as weekly frequency of having at least one portion of each (ordinal: never/seldom/from 1 to 7 days per wk.). We defined residential greenness as the normalized difference vegetation index (within $1 \mathrm{~km}$ buffer of participants' residences), which was calculated from cloudfree satellite imagery in summer of 2014 for the whole country at $30 \times 30 \mathrm{~m}$, and assigned to participants geo-coordinates at SAP2 (Vienneau et al., 2017). Traffic-related air pollutant—nitrogen dioxide $\left(\mathrm{NO}_{2}\right)$-was modeled at participant's residences as outdoor annual mean exposures in 2003. This used a hybrid model that regressed passive sampler measurements against dispersion model estimates (incorporating various emission inventories), seasonal and climatic variables, as well as traffic and land use characteristics (e.g. population, elevation, road length, and number of buildings). Adjusted $\mathrm{R}^{2}$ of this hybrid model was 0.8 (Liu et al., 2012). All SAP2 variables considered as potential confounders or modifiers would be included as covariates in the multivariable models.

We also considered at SAP2, potential mediators, which might descend from noise, but precede depression and lie on the causal pathway between both. These included physical activity (Foraster et al., 2016; Gianfredi et al., 2020); body mass index (BMI) (Foraster et al., 2018; Tyrrell et al., 2019); chronic disease (Huang et al., 2010; WHO, 2011) and excessive daytime sleepiness (Basner 2008; Jaussent et al., 2011). We defined physical activity as having $<150 / \geq 150 \mathrm{~min}$. per wk. of moderate to vigorous activity, and defined BMI as the ratio of objectively measured weight and height-squared $\left(\mathrm{kg} / \mathrm{m}^{2}\right)$. We also defined chronic disease as having one of physician-diagnosed asthma, chronic bronchitis, hypertension, cardiovascular disease (CVD), diabetes, stroke, migraine or arthritis; and defined daytime sleepiness as scoring $>10$ on the Epworth's Sleepiness Scale (Johns, 1991). Given the insufficient understanding of the noise-depression causal networks (Clark and Paunovic, 2018; van Kamp et al., 2013), we would-in a more inclusive approach-test the modifying effects of these potential mediators, as part of the effect modification analyses.

\subsection{Data analyses}

\subsubsection{Descriptive statistics}

We summarized the characteristics of included participants at SAP2, stratified by incident depression status at SAP3. Categorical variables are reported as counts and proportions, and $\chi^{2}$ test was used for between group differences. Continuous variables are reported as means and SD, and unpaired $t$-test was used for between group differences. We 
also stratified the same characteristics by groups of combined Lden exposure (zero- to triple-source exposures) and change of residence during follow-up (movers vs. non-movers). We also did same comparisons among the eligible SAPALDIA participants stratified by inclusion status in the present study (included vs. excluded).

\subsubsection{Main associations}

To determine the relationship of road traffic, railway, aircraft noise exposures, and noise annoyance with risk of depression, we applied Poisson regression models to estimate relative risks (RR) of depression and their 95\% confidence intervals (CI), and corrected for the biased variance estimates obtained by applying the Poisson model to binary data (Zou, 2004). We modeled the three source-specific Ldens and noise annoyance individually in separate models (single exposure models); the source-specific Ldens together in one model (multi-exposure Lden model) and the source-specific Ldens and noise annoyance together in one model (multi-exposure model). We performed crude (Model 1) and incremental confounder-adjusted models. Potential confounders included age, sex, educational attainment, neighborhood SEP, study area, smoking status, alcohol, fruit and vegetable intake, and family history of depression (Model 2), and residential greenness and $\mathrm{NO}_{2}$ (Model 3; main model). Participants with truncated Lden values were captured in the regression models using a source-specific truncation indicator in line with our previous studies (Eze et al., 2017a; Foraster et al., 2017).

In sensitivity analyses, we tested linearity of associations by including thin-plate smoothing splines of noise metrics to the multi-exposure model. We also tested, in the subsample that had complete noise exposure and annoyance data at follow-up, the stability of results when change in exposures were additionally adjusted for, and explored the potential effect of clustering by area, using a model with random intercept at the level of the study area. We explored potential selection bias by comparing the consistency of the crude model in the included vs. the excluded participants, and by inversely weighting the study sample using probability weights (of selection for the present study) derived from eligible SAP1 participants. We tested consistency of associations using an alternative incidence of depression that considered only physician diagnosis and antidepressants (but not the mental health scores).

In further analyses, we estimated cumulative risk of transportation Lden in relation to depression using a post-estimation linear combination of the mutually adjusted Lden coefficients, computation of the $95 \%$ $\mathrm{CI}$, and exponentiation to relative risks, as described in previous studies (Crouse et al., 2015; Klompmaker et al., 2019). We also estimated cumulative risk using the four-level categorical combined transportation Lden as indicator of cumulative exposure (with "zero-source exposure" as the reference group; see Section 2.3) in the main model (Pyko et al., 2017). Both linear and categorical cumulative risks assumed additive effects of the source-specific Ldens, and were estimated using both the multi-exposure Lden model (i.e. model without annoyance) and the multi-exposure model (i.e. model with noise annoyance).

\subsubsection{Effect mediation}

We investigated indirect effects of source-specific Lden to identify potentially mediating pathways of noise exposure on risk of depression. We focused the analyses on noise annoyance, BMI and sufficient physical activity, which capture in part, attributes of chronic diseases and excessive daytime sleepiness, and are likely more robust to reverse causation with depression. We however, included chronic diseases and daytime sleepiness in the effect modification analyses (see Section 2.6.4).

We used generalized structural equation model (GSEM) to estimate the indirect effect of mutually adjusted source-specific Lden with the potential mediators, using the multi-exposure Lden model. GSEM offers generalized linear response functions (with options to handle distribution family and link functions), which enable the modelling of categorical outcomes, mediators and covariates (Huber, 2013). We tested the mediators separately (single mediation) and simultaneously (parallel mediation) in order to estimate the independent contribution of each path. We specified mediator models using robust Poisson models for noise annoyance and physical activity, and linear models for BMI. We used Poisson model for noise annoyance and physical activity given the discrete distribution of noise annoyance, the high prevalence of physical activity, and the compatibility with Poisson-based outcome model estimates, toward minimizing bias in the standard errors. Both mediator and depression models contained the same covariates as the multi-exposure Lden model, but the depression model additionally contained the mediator(s). We computed the indirect paths, and generated their standard errors using bias-corrected bootstrapping method with 5,000 replications. We considered an indirect path to be mediated if it significantly differed from the null (Zhao et al., 2010).

\subsubsection{Effect modification}

To investigate their influence on the individual susceptibility to source-specific Lden and noise annoyance at baseline toward risk of depression at follow-up, we performed subgroup analyses of the potential modifiers (see Section 2.5) using the multi-exposure main model. We however focused these analyses to the common (and prospectively evidenced) risk factors for depression including sex (Hyde and Mezulis, 2020), overweight/obesity [BMI > $25 \mathrm{~kg} / \mathrm{m}^{2}$ ] (Luppino et al., 2010; Tyrrell et al., 2019), physical activity (Gianfredi et al., 2020), excessive daytime sleepiness (Jaussent et al., 2011), and chronic diseases (Huang et al., 2010). We also performed subgroup analyses along two quantiles of competing environmental exposures including residential greenness (Banay et al., 2019) and $\mathrm{NO}_{2}$ (Antonsen et al., 2020). We tested the sub-group differences via multiplicative interaction terms between the noise metrics and the potential modifiers.

Main association, effect mediation and effect modification were also limited to the non-movers-with potentially lower exposure misclassification. Estimates of associations are presented as increase or decrease in RR (95\% CI) of depression and per $10 \mathrm{~dB}$ increase in Lden and per 1-point difference in noise annoyance, unless stated otherwise. We performed the analyses using Stata version 15 (Stata Corporation, College Station, TX) and R version 3.5.1 (R Foundation for Statistical Computing, Vienna), and considered results of main associations and interactions to be statistically significant at two-sided alpha values of 0.05 and 0.1 (Bross, 1971), respectively.

\section{Results}

\subsection{Descriptive statistics}

Mean (SD) road traffic, aircraft, railway Lden and noise annoyance among 4,581 included participants (aged 29-73 years) was 54.7 (8) dB, 35.2 (9) dB, 36.7 (9) dB and 2.5 (3) respectively (Table 1). Table S1 shows the correlation matrix of the study variables. Road traffic Lden had the strongest correlations with noise annoyance ( $r=0.33$ ) compared to aircraft Lden $(r=0.07)$ and railway Lden $(r=0.05)$. Ninety percent, $16 \%$ and $19 \%$ of participants were "exposed" ( $\geq 45 \mathrm{~dB}$ ) to road traffic, railway and aircraft Lden, respectively, and $5 \%$ were "exposed" to the three sources (Table S2). Distributions of source-specific Lden and noise annoyance in the entire sample are presented in Fig. S2. Source-specific Lden and noise annoyance were stable over the followup period, with mean (SD) change of $-0.1(6) \mathrm{dB}, 0.3(5) \mathrm{dB},-1.6$ (6) $\mathrm{dB}$ and $-0.6(3)$ for road traffic, aircraft, railway Lden and noise annoyance, respectively.

Incidence of depression was 11 cases per 1,000 person-years. Physician diagnosis, mental health score and antidepressant use comprised $59 \%, 40 \%$ and $34 \%$ of these cases, with $5 \%$ overlap across the three criteria (Fig. S3). Incident cases of depression were more likely women, younger, less educated, smokers or less physically active, but less likely overweight. They also had higher family history of depression and chronic diseases. They were also more likely to be noise 
Table 1

Baseline characteristics of included SAPALDIA participants stratified by incident depression.

\begin{tabular}{|c|c|c|c|}
\hline & No depression & $\begin{array}{l}\text { Incident } \\
\text { depression }\end{array}$ & P-value \\
\hline N (\%) & & & $\chi^{2}$ \\
\hline Women & 2040 (49) & $258(63)$ & $<0.001$ \\
\hline Formal education, $\leq 9$ years & $187(4)$ & $28(7)$ & 0.080 \\
\hline 10-12 years & $2706(65)$ & $266(65)$ & \\
\hline$\geq 13$ years & $1278(31)$ & $116(28)$ & \\
\hline Smoking status, never-smokers & $1954(47)$ & $155(38)$ & $<0.001$ \\
\hline former smokers & $1329(32)$ & $266(32)$ & \\
\hline current smokers & $888(21)$ & $122(30)$ & \\
\hline Alcohol intake $>$ once /day & $1659(40)$ & $152(37)$ & 0.286 \\
\hline Fruit intake $>3$ days/week & $2620(63)$ & $260(63)$ & 0.810 \\
\hline Vegetable intake $>3$ days/ week & $3644(87)$ & $372(91)$ & 0.048 \\
\hline $\begin{array}{l}\text { Moderate to vigorous physical } \\
\text { activity } \geq 150 \mathrm{~min} / \text { week }\end{array}$ & $2946(71)$ & $273(67)$ & 0.091 \\
\hline Doctor-diagnosed chronic disease ${ }^{a}$ & $1473(35)$ & $193(47)$ & $<0.001$ \\
\hline Overweight or obesity ${ }^{\mathrm{b}}$ & $2193(53)$ & $186(46)$ & 0.008 \\
\hline Family history of depression & $474(11)$ & $103(25)$ & $<0.001$ \\
\hline Daytime sleepiness ${ }^{\mathrm{c}}$ & $3372(88)$ & $328(87)$ & 0.269 \\
\hline Study area, Basel & $522(12)$ & $63(15)$ & $<0.001$ \\
\hline Wald & $827(20)$ & $68(16)$ & \\
\hline Davos & $387(9)$ & $24(6)$ & \\
\hline Lugano & $567(14)$ & $36(9)$ & \\
\hline Montana & $363(9)$ & $50(12)$ & \\
\hline Payerne & 539 (13) & $56(14)$ & \\
\hline Aarau & $676(16)$ & $57(14)$ & \\
\hline Geneva & $290(7)$ & $56(14)$ & \\
\hline Non-movers over follow-up period & $2642(64)$ & $243(59)$ & 0.073 \\
\hline Exposed, road Lden $\geq 45 \mathrm{~dB}$ & $3766(90)$ & $373(91)$ & 0.654 \\
\hline Exposed, aircraft Lden $\geq 45 \mathrm{~dB}$ & $761(18)$ & $97(24)$ & 0.007 \\
\hline $\begin{array}{l}\text { Exposed, railway Lden } \geq 45 \mathrm{~dB} \\
\text { Mean (SD) }\end{array}$ & $698(17)$ & $54(13)$ & $\begin{array}{l}0.063 \\
t \text {-test }\end{array}$ \\
\hline Age (years) & $52(11)$ & $50(11)$ & 0.023 \\
\hline Body mass index $\left(\mathrm{kg} / \mathrm{m}^{2}\right)^{\mathrm{b}}$ & 25.7 (4) & $25.6(5)$ & 0.713 \\
\hline $\begin{array}{l}\text { Neighborhood socio-economic } \\
\text { position (\%) }\end{array}$ & $64(10)$ & $64(10)$ & 0.325 \\
\hline $\begin{array}{l}\text { Greenness index in } 1 \mathrm{~km} \text { residential } \\
\text { buffer }\end{array}$ & $0.59(0.1)$ & $0.58(0.1)$ & 0.408 \\
\hline Nitrogen dioxide $\left(\mu \mathrm{g} / \mathrm{m}^{3}\right)$ & $22.5(10)$ & $22.3(10)$ & 0.692 \\
\hline Noise annoyance & $2.5(3)$ & $2.9(3)$ & 0.004 \\
\hline Road traffic Lden (dB) & $54.7(8)$ & $55.1(8)$ & 0.357 \\
\hline Aircraft Lden (dB) & $35.0(8)$ & $36.3(9)$ & 0.005 \\
\hline Railway Lden (dB) & $36.8(9)$ & $35.8(9)$ & 0.037 \\
\hline $\begin{array}{l}\text { Change in noise annoyance over } \\
\text { follow-up }{ }^{d}\end{array}$ & $-0.6(3)$ & $-0.9(3)$ & 0.075 \\
\hline $\begin{array}{l}\text { Change in road traffic Lden over } \\
\text { follow-up }(\mathrm{dB})^{\text {e }}\end{array}$ & $-0.07(6)$ & $-0.4(6)$ & 0.289 \\
\hline $\begin{array}{l}\text { Change in aircraft Lden over follow- } \\
\text { up }(\mathrm{dB})^{\text {e }}\end{array}$ & $0.3(5)$ & $-0.1(5)$ & 0.165 \\
\hline $\begin{array}{l}\text { Change in railway Lden over follow- } \\
\text { up }(\mathrm{dB})^{\text {e }}\end{array}$ & $-1.7(6)$ & $-0.9(6)$ & 0.019 \\
\hline
\end{tabular}

SAPALDIA: Swiss Cohort Study on Air Pollution and Lung and Heart Diseases in Adults. Lden: day-evening-night noise level. Depression defined as doctor-diagnosed depression or use of medication or SF-36 mental health score $<50$. $\mathrm{N}=4,581$ for all variables except for $\mathrm{b}(\mathrm{n}=4,558), \mathrm{c}(\mathrm{n}=4,191)$, d ( $\mathrm{n}=3,982)$ and $\mathrm{e}(\mathrm{n}=4,555)$.

a Doctor-diagnosed chronic disease defined as self-reported physician diagnosis of asthma, chronic bronchitis, hypertension, cardiovascular disease, diabetes, stroke, migraine, and arthritis.

b Overweight/obesity defined as body mass index $>25 \mathrm{~kg} / \mathrm{m}^{2}$.

c Daytime sleepiness defined as scoring $>10$ on the Epworth's sleepiness scale.

annoyed, have higher aircraft, but lower railway noise exposures. There were no significant differences in their residential exposure to road traffic noise, $\mathrm{NO}_{2}$ and greenness (Table 1).

Excluded participants were older, less educated, from urban areas, less physically active and more overweight. They also had higher road traffic noise, aircraft noise and air pollution exposures and lived in less green areas. There was no significant difference in the distribution of sex, change of residence, noise annoyance, and the proportion of incident depression cases between the included and excluded participants (Table S3).

\subsection{Main associations}

In single-exposure models, associations (per $10 \mathrm{~dB}$ ) of road traffic and aircraft Lden with risk of depression tended to be positive whereas that of railway Lden tended to be negative (Table 2). Adjustment for socio-demographic, lifestyle factors and family history of depression respectively attenuated and increased the effect estimates for road traffic and aircraft Lden. Further adjustment for residential greenness and $\mathrm{NO}_{2}$ increased the effect estimate for road traffic, but decreased those of aircraft Lden. We observed a positive and statistically significant association between noise annoyance (per 1-point difference) and the risk of depression, which was particularly stable to confounder adjustments. These associations were stable to further adjustments for BMI and physical activity. In non-movers, we also observed a positive statistically significant association of noise annoyance, and a positive association of aircraft Lden with risk of depression. However, associations of road traffic Lden and railway Lden approached the null.

In the multi-exposure Lden model (Table 2), we observed associations that were similar to the single exposure models, with respective RR $(95 \% \mathrm{CI})$ of $1.07(0.93,1.22), 1.20(0.92,1.55)$ and $0.88(0.76$, 1.03) for road traffic, aircraft and railway Lden. Adjusting for BMI and physical activity decreased only the estimates for road traffic Lden. In the multi-exposure model (i.e. including noise annoyance), the estimates for road traffic and aircraft Lden further decreased $\left[R R_{\text {road traffic }}\right.$ : $1.02(0.89,1.17)$; $\left.R_{\text {aircraft: }} 1.16(0.90,1.49)\right]$, whereas those for railway Lden and noise annoyance remained unchanged from the single-exposure model $\left[\mathrm{RR}_{\text {railway }}: 0.88(0.75,1.02)\right.$; $\mathrm{RR}_{\text {annoyance }}: 1.05$ $(1.01,1.08)]$. In the non-mover multi-exposure model, we also observed a positive statistically significant association for noise annoyance [RR: $1.04(1.00,1.08)]$ and positive association for aircraft Lden [(RR: $1.28(0.95,1.73)]$ whereas those of road traffic and railway Lden approached the null.

Smoothing splines of source-specific transportation noise exposure and noise annoyance (based on the adjusted multi-exposure model) showed significant linear trend of noise annoyance in the entire sample ( $\left.p_{\text {trend }}=0.008\right)$, but some non-linear trend in non-movers $\left(p_{\text {trend }}=0.049\right)$. Aircraft Lden also showed initial linear trend $\left(p_{\text {trend }}=0.14\right)$, with some threshold effect at $\sim 48 \mathrm{~dB}$, both in the entire sample and in non-movers (Fig. 1). Further sensitivity analyses showed that risk estimates were stable, but weaker, when applying the random effect of study area and when excluding participants with physician-diagnosed chronic disease. Risk estimates were also stable to inverse probability weighting, however, the crude estimate for aircraft Lden in the excluded participants was negative. Excluding the mental health score in depression identification strengthened the Lden and weakened the annoyance estimates. Adjusting for change in exposures over follow-up strengthened the aircraft Lden effects, reaching statistical significance in non-movers (Table 2), where sensitivity analyses were similarly robust (Table S4).

In evaluating more complex exposure situations, the cumulative risks of transportation Lden (based on the multi-exposure Lden model) showed additive tendencies for both linear and categorical risks, which were more distinct in non-movers than in the general sample. Among the non-movers, the cumulative risks per $10 \mathrm{~dB}$ of any transportation Lden was $1.31(0.90,1.91)$. At an exposure threshold $\geq 45 \mathrm{~dB}$, road traffic and aircraft Lden, but not railway Lden were positively associated with depression risk. Participants having single-source, doublesource and triple-source exposures ( $\geq 45 \mathrm{~dB}$ ), had respective RR of 1.91 (95\% CI: 1.00, 3.63), 1.95 (95\% CI: 0.98, 3.84) and 2.29 (95\% CI: 1.02 , 5.14 ) compared to participants having zero-source exposure ( $\geq 45 \mathrm{~dB}$ ). These associations were stable to adjustment for noise annoyance, however, with wide CIs (Table 3 ). 
Table 2

Association between transportation noise exposure, annoyance and incidence of depression: single and multi-exposure models.

\begin{tabular}{|c|c|c|c|c|c|}
\hline & Model & $\begin{array}{l}\text { Road traffic Lden } \\
\text { IRR }(95 \% \text { CI) }\end{array}$ & $\begin{array}{l}\text { Aircraft Lden } \\
\text { IRR }(95 \% \mathrm{CI})\end{array}$ & $\begin{array}{l}\text { Railway Lden } \\
\text { IRR (95\% CI) }\end{array}$ & $\begin{array}{l}\text { Noise annoyance } \\
\text { IRR }(95 \% \text { CI) }\end{array}$ \\
\hline \multicolumn{6}{|l|}{ Single exposure, all } \\
\hline & Model 1 & $1.06(0.94,1.19)$ & $1.06(0.87,1.31)$ & $0.90(0.77,1.05)$ & $1.05(1.01,1.08)^{* *}$ \\
\hline & Model 2 & $1.01(0.89,1.14)$ & $1.25(0.97,1.60)$ & $0.88(0.75,1.03)$ & $1.04(1.01,1.07)^{* *}$ \\
\hline & Model 3 & $1.06(0.93,1.22)$ & $1.19(0.93,1.53)$ & $0.88(0.75,1.03)$ & $1.05(1.02,1.08)^{* * *}$ \\
\hline & Model 4 & $1.06(0.93,1.21)$ & $1.19(0.93,1.52)$ & $0.87(0.74,1.02)$ & $1.05(1.02,1.08)^{* *}$ \\
\hline & Model 5 & $1.05(0.90,1.22)$ & $1.22(0.93,1.60)$ & $0.91(0.77,1.07)$ & $1.06(1.01,1.10)^{* *}$ \\
\hline & Model 6 & $1.00(0.84,1.19)$ & $1.31(0.97,1.76)^{*}$ & $0.99(0.83,1.19)$ & $1.04(1.00,1.08)^{* * *}$ \\
\hline \multicolumn{6}{|l|}{ Multi-exposure Lden, all } \\
\hline & Model 1 & $1.06(0.93,1.19)$ & $1.12(0.91,1.38)$ & $0.89(0.76,1.04)$ & n.a. \\
\hline & Model 2 & $1.03(0.90,1.16)$ & $1.25(0.96,1.61)^{*}$ & $0.88(0.76,1.03)$ & n.a. \\
\hline & Model 3 & $1.07(0.93,1.22)$ & $1.20(0.92,1.55)$ & $0.88(0.76,1.03)$ & n.a. \\
\hline & Model 4 & $1.03(0.91,1.17)$ & $1.21(0.93,1.56)$ & $0.88(0.76,1.03)$ & n.a. \\
\hline & Model 5 & $1.05(0.90,1.22)$ & $1.23(0.93,1.63)$ & $0.91(0.77,1.08)$ & \\
\hline & Model 6 & $1.01(0.84,1.20)$ & $1.31(0.97,1.76)^{*}$ & $1.00(0.83,1.19)$ & n.a. \\
\hline \multicolumn{6}{|l|}{ Multi-exposure, all } \\
\hline & Model 1 & $1.00(0.88,1.13)$ & $1.13(0.92,1.39)$ & $0.89(0.76,1.04)$ & $1.05(1.01,1.08)^{* *}$ \\
\hline & Model 2 & $0.98(0.86,1.11)$ & $1.23(0.95,1.58)$ & $0.88(0.75,1.02)$ & $1.04(1.01,1.08)^{* *}$ \\
\hline & Model 3 & $1.02(0.89,1.17)$ & $1.17(0.90,1.50)$ & $0.88(0.75,1.02)$ & $1.05(1.02,1.08)^{* *}$ \\
\hline & Model 4 & $1.02(0.89,1.17)$ & $1.16(0.91,1.49)$ & $0.87(0.74,1.02)$ & $1.05(1.02,1.08)^{* * *}$ \\
\hline & Model 5 & $0.99(0.84,1.16)$ & $1.20(0.91,1.58)$ & $0.91(0.77 .1 .07)$ & $1.06(1.01,1.11)^{* *}$ \\
\hline \multicolumn{6}{|l|}{ Multi-exposure, non-movers } \\
\hline & Model 1 & $0.93(0.78,1.10)$ & $1.12(0.87,1.44)$ & $1.02(0.85,1.22)$ & $1.06(1.02,1.10)^{* * *}$ \\
\hline & Model 2 & $0.92(0.77,1.10)$ & $1.34(0.99,1.82)$ & $1.00(0.83,1.19)$ & $1.04(1.00,1.08)^{*}$ \\
\hline & Model 3 & $0.96(0.80,1.15)$ & $1.27(0.95,1.71)$ & $0.99(0.83,1.19)$ & $1.04(1.00,1.09)^{* *}$ \\
\hline & Model 4 & $0.96(0.80,1.16)$ & $1.25(0.93,1.67)$ & $0.99(0.83,1.19)$ & $1.05(1.00,1.09)^{* *}$ \\
\hline & Model 5 & $1.00(0.82,1.22)$ & $1.45(1.05,1.99)^{* * *}$ & $0.97(0.80,1.17)$ & $1.04(0.98,1.11)$ \\
\hline
\end{tabular}

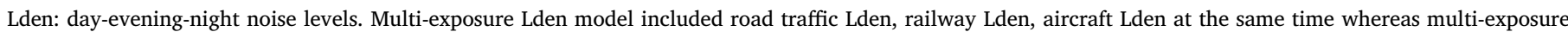

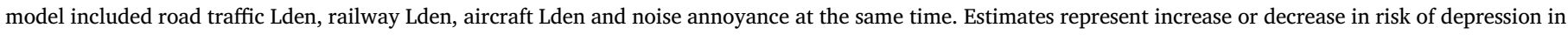

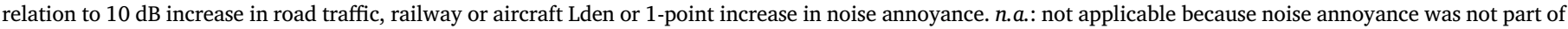
the model. *p-value $<0.1, * *$ p-value $<0.05$.

Model 1: unadjusted (also included source-specific truncation indicators).

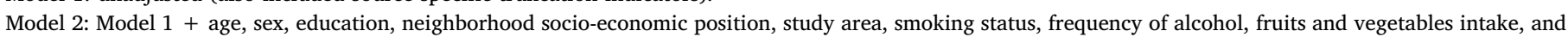
family history of depression.

Model 3: Model $2+$ residential greenness and nitrogen dioxide (main model; $n=4,581$ ).

Model 4: Model $3+$ body mass index and physical activity $(n=4,550)$.

Model 5: Model $3+$ change in source-specific Lden (and noise annoyance) over follow-up period ( $\left.\mathrm{n}_{\text {all }}=3,961 ; \mathrm{n}_{\text {non-movers }}=2,469\right)$.

Model 6: Model 3 in non-movers $(n=2,885)$.

\subsection{Effect mediation}

We observed some independent associations of source-specific Lden with the potential mediators. For the noise annoyance model, the estimates for road traffic and aircraft Lden were positive and statistically significant, but railway Lden did not reach statistical significance. For the BMI model, the estimates for road traffic Lden were positive and statistically significant, but those of aircraft and railway Lden were negative. For the physical activity model, the estimates for road traffic and railway Lden were negative whereas those of aircraft Lden were positive, but none reached statistical significance (Table 4).

In single mediation models, we observed statistically significant indirect effect of road traffic and aircraft Lden via noise annoyance, on risk of depression. The indirect effects via BMI and physical activity were statistically non-significant. Nevertheless, both paths showed consistent positive effects for road traffic Lden (Table 4). Parallel mediation models were rather consistent with single mediation models. Here, the noise annoyance paths remained significant for road traffic and aircraft Lden (Fig. 2). Estimates of indirect effects-in both single and parallel mediation models-were also consistent, in non-movers (Table 4).

\subsection{Effect modification}

We limited effect modification analyses to non-movers given the observation of stronger noise associations in the main and mediation analyses. For some modifiers, subgroup estimates were directionally inconsistent across exposures. We observed tendencies for stronger associations of road traffic Lden among participants who were not overweight $\left(p_{\text {interaction }}=0.061\right)$ or had no daytime sleepiness $\left(p_{\text {interaction }}=0.042\right)$, and stronger associations of railway Lden in men $\left(p_{\text {interaction }}=0.026\right)$ or overweight participants $\left(p_{\text {interaction }}=0.031\right)$. However, subgroup estimates for both exposures did not reach statistical significance. Aircraft Lden effects were stronger with higher $\mathrm{NO}_{2}$ exposure $\left(p_{\text {interaction }}=0.054\right)$. Although interaction terms were nonsignificant, we observed positive associations of aircraft Lden and incident depression among participants who were overweight, or those who had lower residential greenness (Table S5). We observed stronger noise annoyance effects among participants reporting insufficient physical activity $\left(p_{\text {interaction }}=0.07\right)$ or excessive daytime sleepiness $\left(p_{\text {interaction }}=0.007\right)$. There were stronger effects of noise annoyance among men and among participants without chronic disease, but interaction terms were not statistically significant (Table S5).

\section{Discussion}

\subsection{Summary of findings and contextual relevance}

Transportation noise annoyance was associated with risk of depression whereas road traffic and aircraft noise level had mostly indirect associations. In non-movers, aircraft, but not road traffic or railway noise exposure showed direct associations with incident depression, and we observed some additive tendencies where individuals exposed to multiple noise sources had higher risk of depression, also independent of noise annoyance. All observations were robust to adjustment for common depression risk factors, air pollution, greenness 
A

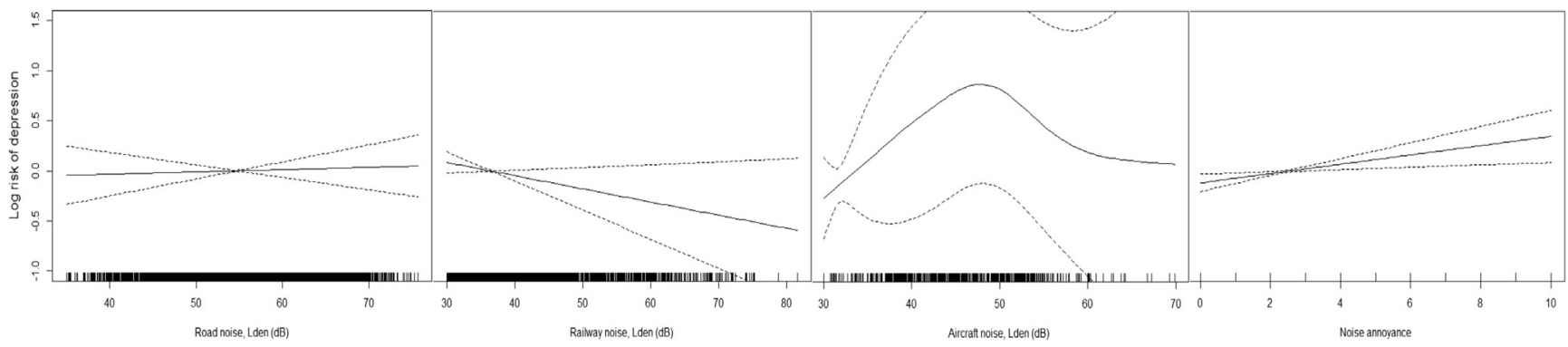

B

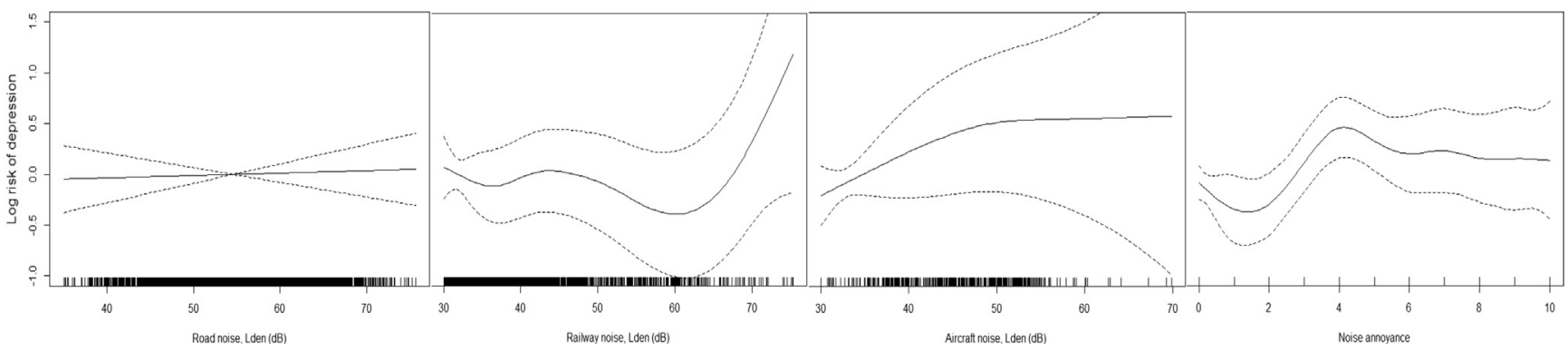

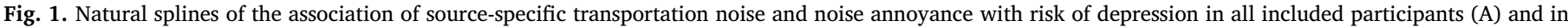

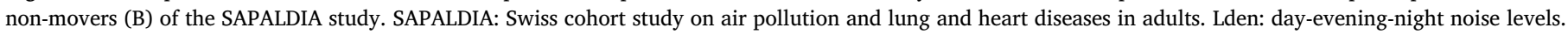

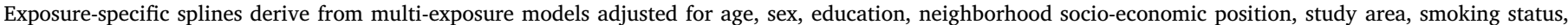

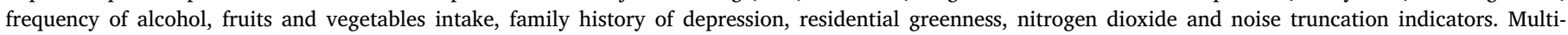
exposure models included all four noise metrics at the same time. $\mathrm{N}(\mathrm{A})=4,581 ; \mathrm{N}(\mathrm{B})=2,885$ participants.

and other contextual covariates.

Our findings with noise annoyance are generally consistent with previous studies. Environmental noise annoyance that included transportation, neighborhood and occupational noise was associated with prevalent depression (Beutel et al., 2016; Yoon et al., 2014). Positive links of neighborhood and road traffic noise annoyance (Hammersen et al., 2016; Jensen et al., 2018), aircraft noise annoyance (Baudin et al., 2018; Floud et al., 2011; Schreckenberg et al., 2010) and general noise perception (Rocha et al., 2012) with broader mental health were also reported. There is therefore the possibility that noise annoyance reflects better the true exposure on a population average where for instance, people in situations of modeled low noise with ineffective insulation would be highly annoyed and vice versa. The aspect of noise annoyance that captures sensitivity may have also contributed to the findings, given the relevance of noise sensitivity to mental health (Fyhri and Klæboe 2009; van Kamp et al., 2013). The apparent relevance of noise annoyance on mental health might also explain the positive findings with aircraft, but not road or railway noise, given that aircraft noise, elicits higher annoyance at the same level, than road traffic and railway noise, due to its temporal structure (Brink et al., 2019; Wothge

Table 3

Risk of depression in relation to combined exposure to transportation noise sources in the SAPALDIA study.

\begin{tabular}{|c|c|c|c|c|c|}
\hline & & \multicolumn{2}{|l|}{ All } & \multicolumn{2}{|l|}{ Non-movers } \\
\hline & & $\begin{array}{l}\text { Model } 1 \\
\text { RR }(95 \% \text { CI) }\end{array}$ & $\begin{array}{l}\text { Model } 2 \\
\text { RR }(95 \% \text { CI) }\end{array}$ & $\begin{array}{l}\text { Model } 1 \\
\text { RR }(95 \% \text { CI) }\end{array}$ & $\begin{array}{l}\text { Model } 2 \\
\text { RR }(95 \% \text { CI) }\end{array}$ \\
\hline \multirow[t]{4}{*}{ Per $10 \mathrm{~dB}$ Lden } & Road traffic Lden ${ }^{a}$ & $1.07(0.93,1.22)$ & $1.02(0.89,1.17)$ & $1.01(0.84,1.20)$ & $0.96(0.80,1.15)$ \\
\hline & Aircraft Lden ${ }^{\mathrm{a}}$ & $1.20(0.92,1.55)$ & $1.17(0.90,1.50)$ & $1.31(0.97 .1 .76)^{*}$ & $1.27(0.95,1.71)$ \\
\hline & Railway Lden ${ }^{\mathrm{a}}$ & $0.88(0.76,1.03)$ & $0.88(0.75,1.02)$ & $1.00(0.83,1.19)$ & $0.99(0.83,1.19)$ \\
\hline & Cumulative risk $^{\mathrm{b}}$ & $1.13(0.81,1.58)$ & $1.04(0.75,1.46)$ & $1.31(0.90,1.91)$ & $1.21(0.83,1.78)$ \\
\hline \multirow[t]{4}{*}{ Lden $\geq 45$ vs. $<45 \mathrm{~dB}$} & Road traffic Lden & $1.09(0.78,1.52)$ & $1.04(0.75,1.45)$ & $1.27(0.81,1.99)$ & $1.22(0.78,1.91)$ \\
\hline & Aircraft Lden & $1.26(0.90,1,75)$ & $1.24(0.89,1.72)$ & $1.53(1.02,2.28)^{* * *}$ & $1.51(1.01,2.24)^{* *}$ \\
\hline & Railway Lden & $0.81(0.61,1.08)$ & $0.81(0.61,1.07)$ & $0.93(0.67,1.30)$ & $0.93(0.67,1.30)$ \\
\hline & Cumulative risk ${ }^{\mathrm{b}}$ & $1.11(0.66,1.88)$ & $1.04(0.62,1.76)$ & $1.81(0.96,3.44) *$ & $1.71(0.90,3.24)$ \\
\hline \multirow[t]{4}{*}{ Cumulative risk, Lden $\geq 45 \mathrm{~dB}$} & Zero-source $^{c}$ & Ref. & Ref. & Ref. & Ref. \\
\hline & Single-source & $1.17(0.79,1.74)$ & $1.13(0.76,1.68)$ & $1.91(1.00,3.63)^{* *}$ & $1.85(0.98,3.51)^{*}$ \\
\hline & Double-source & $1.15(0.74,1.79)$ & $1.10(0.71,1.71)$ & $1.95(0.98,3.84)^{*}$ & $1.87(0.95,3.68)^{*}$ \\
\hline & Triple-source & $1.03(0.56,1.91)$ & $0.98(0.52,1.79)$ & $2.29(1.02,5.14)^{* * *}$ & $2.16(0.96,4.85)^{*}$ \\
\hline
\end{tabular}

Lden: day-evening-night noise levels. Estimates represent increase or decrease in risk of depression in relation to $10 \mathrm{~dB}$ increase in road traffic, railway or aircraft Lden or in noise exposure groups compared to the reference group. ${ }^{*}$-value $<0.1$, ${ }^{* *}$ p-value $<0.05$.

Model 1: adjusted for age, sex, education, neighborhood socio-economic position, study area, smoking status, frequency of alcohol, fruits and vegetables intake, family history of depression, residential greenness and nitrogen dioxide.

Model 2: Model $1+$ noise annoyance.

${ }^{a}$ Multi-exposure model containing road traffic, aircraft and railway Lden at the same time.

b Calculated as the exponentiated, linear combination of the source-specific coefficients from multi-exposure model.

c Zero-source refers to exposure to all three source-specific Lden at $<45 \mathrm{~dB}$. Single-, Double- and triple-source refer to exposure to one, two and three sourcespecific Ldens at $\geq 45 \mathrm{~dB}$. 
Table 4

Mediation of transportation noise exposure and risk of depression by noise annoyance, body mass index and physical activity, in the SAPALDIA study.

\begin{tabular}{|c|c|c|c|c|c|c|}
\hline & & Exposure & Noise annoyance & Body mass index & Sufficient physical activity & Total indirect effect ${ }^{\mathrm{a}}$ \\
\hline \multirow[t]{11}{*}{ All } & Single mediator models ${ }^{b}$ & & $\beta(95 \% \mathrm{CI})$ & $\beta(95 \% \mathrm{CI})$ & $\beta(95 \% \mathrm{CI})$ & $\beta(95 \% \mathrm{CI})$ \\
\hline & Association with mediator ${ }^{c}$ & Road traffic Lden & $0.373(0.325,0.420)^{* *}$ & $0.161(0.000,0.322)^{* *}$ & $-0.005(-0.032,0.021)$ & n.a. \\
\hline & & Aircraft Lden & $0.154(0.051,0.257)^{* *}$ & $\begin{array}{l}-0.386(-0.786 \\
0.015)^{*}\end{array}$ & $0.015(-0.054,0.084)$ & n.a. \\
\hline & & Railway Lden & $0.019(-0.024,0.062)$ & $-0.057(-0.222,0.108)$ & $-0.004(-0.032,0.023)$ & n.a. \\
\hline & Indirect effect of mediator ${ }^{\mathrm{d}}$ & Road traffic Lden & $0.017(0.005,0.029) * *$ & $0.002(-0.001,0.009)$ & $0.001(-0.003,0.009)$ & n.a. \\
\hline & & Aircraft Lden & $0.007(0.002,0.017)^{* *}$ & $-0.006(-0.025,0.002)$ & $-0.002(-0.022,0.007)$ & n.a. \\
\hline & & Railway Lden & $0.001(-0.001,0.004)$ & $-0.001(-0.007,0.001)$ & $0.001(-0.003,0.009)$ & n.a. \\
\hline & Parallel mediator model ${ }^{\mathrm{e}}$ & & & & & \\
\hline & Indirect effect of mediator ${ }^{\mathrm{d}}$ & Road traffic Lden & $0.018(0.006,0.029)^{* *}$ & $0.002(-0.001,0.010)$ & $0.001(-0.003,0.008)$ & $0.021(0.008,0.036)^{* *}$ \\
\hline & & Aircraft Lden & $0.007(0.002,0.017)^{* *}$ & $-0.006(-0.02,0.001)$ & $-0.002(-0.024,0.007)$ & $-0.001(-0.024,0.016)$ \\
\hline & & Railway Lden & $0.001(-0.001,0.004)$ & $-0.001(-0.007,0.001)$ & $0.001(-0.003,0.009)$ & $0.001(-0.006,0.008)$ \\
\hline \multirow[t]{11}{*}{ Non-movers } & Single mediator models ${ }^{\mathrm{b}}$ & & & & & \\
\hline & Association with mediator ${ }^{c}$ & Road traffic Lden & $0.381(0.322,0.439)^{* *}$ & $0.219(0.004,0.434)^{* *}$ & $-0.022(-0.058,0.013)$ & n.a. \\
\hline & & Aircraft Lden & $0.225(0.099,0.353)^{* *}$ & $-0.315(-0.858,0.229)$ & $0.001(-0.086,0.088)$ & n.a. \\
\hline & & Railway Lden & $-0.001(-0.055,0.054)$ & $-0.106(-0.313,0.100)$ & $0.008(-0.026,0.042)$ & n.a. \\
\hline & Indirect effect of mediator ${ }^{d}$ & Road traffic Lden & $0.017(0.001,0.033)^{* *}$ & $0.002(-0.004,0.012)$ & $0.003(-0.002,0.019)$ & n.a. \\
\hline & & Aircraft Lden & $0.010(0.001,0.024)^{* * *}$ & $-0.002(-0.028,0.005)$ & $-0.0001(-0.020,0.016)$ & n.a. \\
\hline & & Railway Lden & $-0.00002(-0.003,0.003)$ & $-0.001(-0.009,0.002)$ & $-0.001(-0.013,0.003)$ & n.a. \\
\hline & Parallel mediator models ${ }^{\mathrm{e}}$ & & & & & \\
\hline & Indirect effect of mediator ${ }^{\mathrm{d}}$ & Road traffic Lden & $0.017(0.001,0.033)^{* *}$ & $0.002(-0.004,0.013)$ & $0.003(-0.002,0.019)$ & $0.023(0.003,0.043)^{* *}$ \\
\hline & & Aircraft Lden & $0.010(0.002,0.025)^{* *}$ & $-0.003(-0.020,0.010)$ & $-0.0001(-0.020,0.018)$ & $0.007(-0.018,0.032)$ \\
\hline & & Railway Lden & $-0.00002(-0.003,0.003)$ & $-0.001(-0.011,0.002)$ & $-0.001(-0.012,0.006)$ & $-0.002(-0.014,0.005)$ \\
\hline
\end{tabular}

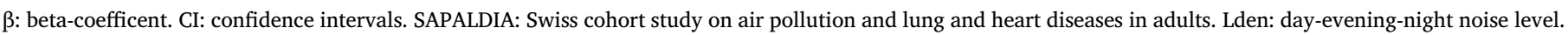

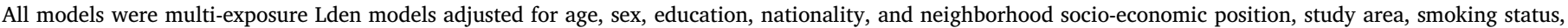

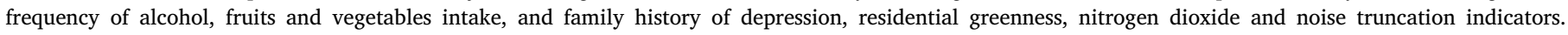
Generalized structural equation models were used for mediation analyses. n.a.: not applicable.

a Estimates derived from non-linear combination of coefficients from the parallel mediation models.

b Models considered one mediator at a time.

c Estimates represent change in mediator variables per $10 \mathrm{~dB}$ increase in Lden exposure. Robust Poisson models were used for noise annoyance and physical activity whereas linear models were used for body mass index.

d Estimates (and bias-corrected confidence intervals) represent the indirect pathway going from source-specific Lden through the mediator variable to risk of depression. Bias-corrected standard errors of the indirect effect were derived using bootstrapping technique with 5000 replications.

e Models contained all three mediators at the same time.

\section{et al., 2017).}

Our findings with source-specific transportation noise levels were less consistent with other studies. While our study and another prospective study (Stansfeld et al., 1996) did not find significant associations with road traffic noise, positive significant associations with risk of depression or anti-depressant use were reported (He et al., 2019; Leijssen et al., 2019; Okokon et al., 2018; Orban et al., 2015; Seidler et al., 2017; Yoshida et al., 1997). Our observation of association between aircraft noise exposure and depression risk in non-movers was concordant (Hiramatsu et al., 1997) and discordant (Baudin et al., 2018; Tarnopolsky et al., 1980; Wright et al., 2018) with previous studies. We could also not replicate the positive findings reported for railway noise in two studies (Klompmaker et al., 2019; Seidler et al., 2017). However, our observation of indirect effects of road traffic noise via noise annoyance agrees with recent findings on mental health in young adults (Dzhambov et al., 2017). In addition, the additive effect of source-specific noise exposure with depression risk agrees with the findings of another study (Seidler et al., 2017) which reported the highest risk among participants exposed to all three transportation noise sources. Interestingly, this additive pattern was also reported for obesity and ischemic heart disease (Pyko et al., 2019; Pyko et al., 2017).

\subsection{Potential mechanisms}

Taken together, the evidence for noise exposure and noise annoyance effects on depression risk remains suggestive. Noise exposure or annoyance reaction creates negative emotions which may relate to depression via alterations in the HPA function and in the neurotransmitter pathways (van den Bosch and Meyer-Lindenberg, 2019). The chronic nature of long-term noise exposure may induce an inflammatory state (Münzel et al., 2017), which also characterizes depression (Raison et al., 2006). Depression is frequently associated with sleep problems (Franzen and Buysse, 2008), which enhances a proinflammatory state (Mullington et al., 2010), and is a frequently reported health effect of noise (Halperin, 2014). Our findings of stronger noise annoyance effects among participants with excessive daytime sleepiness or insufficient physical activity supports these potential mechanisms. We have previously reported noise annoyance to be predictive of insufficient physical activity (Foraster et al., 2016) whereas another study demonstrated that shorter sleep duration enhanced the link between occupational noise annoyance and depression (Yoon et al., 2014). Like insufficient sleep, physical inactivity is related to stress pathway and inflammation, with detrimental effects on mental health (Moylan et al., 2013). Thus, the effect of noise annoyance on depression may be magnified in a background of chronic subclinical inflammation, which also predisposes individuals to CVD (Black and Garbutt, 2002). Also relevant are social mechanisms related to restorative quality of the residential environment, which are increasingly reported as relevant pathways through which traffic exposures impact health (Dzhambov et al., 2018). Poor perceived restorative quality of residential neighborhoods often occur in relation to traffic exposures, with downstream negation of the health benefits of residential satisfaction (von Lindern et al., 2016).

\subsection{Strengths and weaknesses}

Our study has several strengths. To our knowledge, this is the first study investigating the longitudinal mutually independent associations of source-specific transportation noise exposure and noise annoyance, independent of common markers of traffic-related air pollution. Noise exposure was derived from validated Swiss noise calculation models, and assigned to individuals on a very fine spatial scale. The detailed 
A
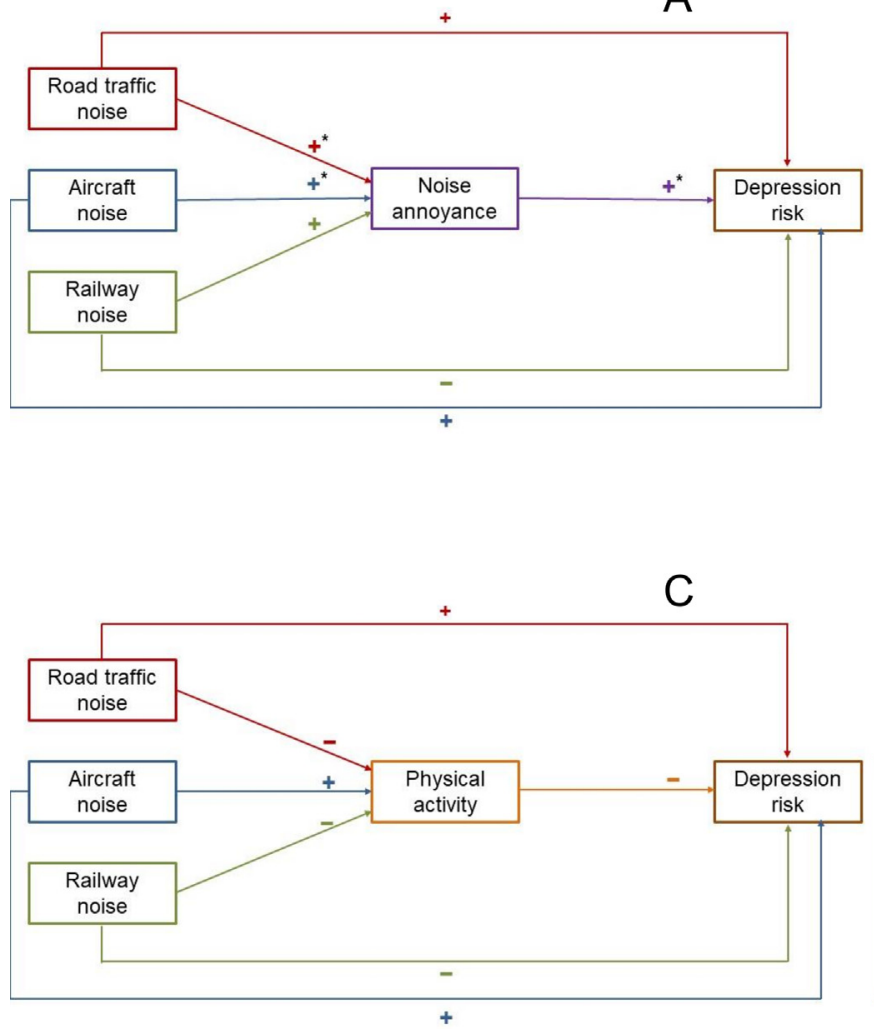

B

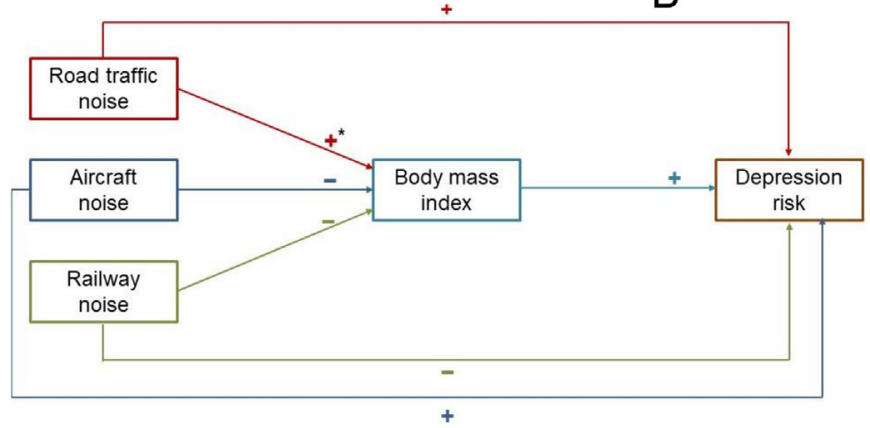

D

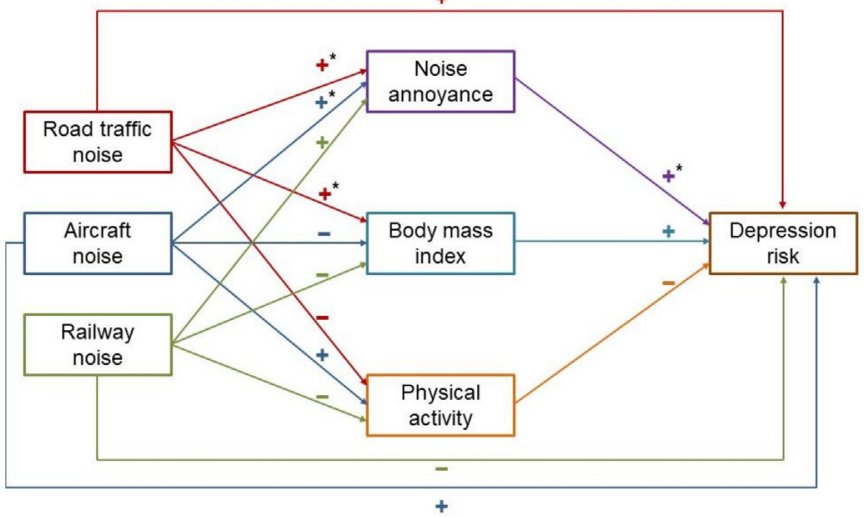

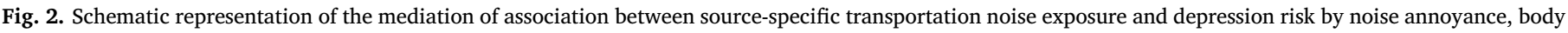

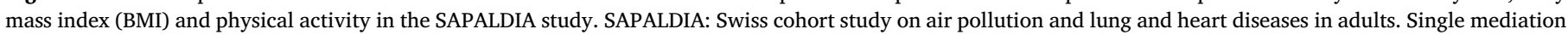

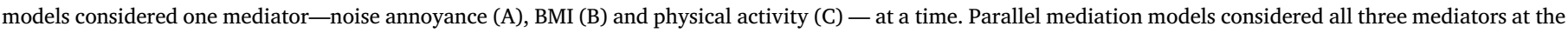

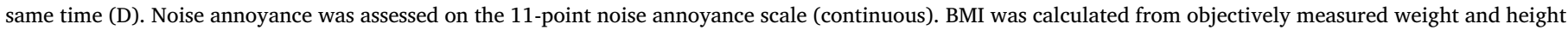

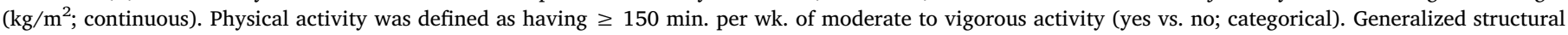

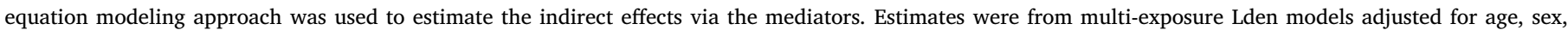

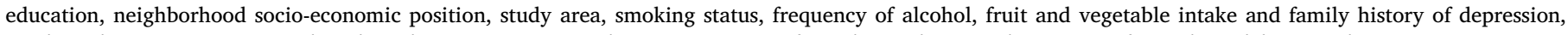

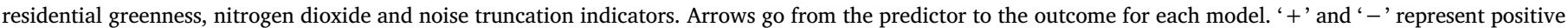
and negative direction of association between variables, respectively. ${ }^{*} p$-value $<0.05$.

phenotypic characterization of the SAPALDIA study allowed the control of potential confounders (including air pollution exposures and residential greenness), and the investigation of effect modification. The incorporated mediation analyses contributes longitudinal evidence on the role of noise annoyance in mediating source-specific noise level effects on depression. The availability of residential history of participants allowed analyses in non-movers, with limited exposure misclassification and more precise long-term noise exposures. The consideration of mental health scores of participants in depression case identification limited outcome misclassification, and in combination with the longitudinal design, minimized reverse causality where people with early symptoms may be more likely noise-annoyed.

The limitations of our study include the relatively low sample size with low number of depression cases-especially in non-movers-and might explain the weak overall associations. Our noise annoyance question, despite the $0-10$ rating scale, specified an open-window context, therefore might not capture overall annoyance. However, this annoyance might be more relevant as it potentially captures indoor annoyance (therefore, population average indoor noise) and indoor restorative quality, which are expected to have more health effects. Furthermore, our findings are consistent with other studies whose noise annoyance assessment might be considered more inclusive. Although we included participants with lower mental health scores as depression cases, we may have misclassified other mental health problems as depression, but depression remains the most prevalent mental health disorder (WHO, 2017), and frequently co-occurs with other mental health problems (Cancino et al., 2018). The limited overlap in the depression components may reflect the difference in duration of depression covered by the different questions in addition to capturing different severities of disease. The short-term duration of the depression symptoms and medication use questions might have underestimated the depression cases, both at baseline and at follow-up. We can therefore not entirely rule out reverse causation of the observed annoyance effects. There is the possibility that mental health may be more of a context than an precise health endpoint, that together with noise sensitivity, puts people in a generally more vulnerable state, which makes them more annoyed than others (Fyhri and Klæboe, 2009; van Kamp et al., 2013). The integration of the mental health scores in our case identification should have reduced this bias. Nevertheless, the absence of time-varying covariates in our models makes it difficult to confirm the longitudinal causal direction of associations in this study. Input data errors may have influenced our noise exposure assignment, but we expect this potential misclassification to be random, and to bias the reported estimates towards null. Our findings of source-specific noise effects in non-movers may not be generalizable to the entire cohort given the inverse direction of unadjusted aircraft noise effects in the excluded participants, as well as the observed differences between movers and non-movers (Table S6). Movers tended to move to quieter areas and this might have led to overestimation bias of noise effects in this group if there had been no random misclassification. In line with our previous report (Eze et al., 2017b), it is more likely that attenuation bias due to random misclassification had a stronger impact on our results than any potential bias due to differential misclassification. 


\section{Conclusions}

Our findings demonstrate that both transportation noise level and noise annoyance are linked to the risk of depression, especially in nonmovers where noise levels showed additive tendencies. The observed mediation of source-specific exposures by noise annoyance, as well as the stronger noise annoyance effects on individuals who have insufficient physical activity or excessive daytime sleepiness shed light on the potential pathways linking transportation noise, annoyance and poor mental health. More longitudinal evidence with larger sample sizes is needed to confirm and better understand these findings. Evidence is also warranted from low-and middle-income countries currently facing a high burden of depression, concurrent with poorly regulated noise and air pollution levels, toward an improved global understanding and targeted public health control of these factors.

\section{CRediT authorship contribution statement}

Ikenna C. Eze: Conceptualization, Methodology, Formal analysis, Data curation, Writing - original draft. Maria Foraster: Methodology, Data curation, Writing - review \& editing. Emmanuel Schaffner: Methodology, Data curation, Writing - review \& editing. Danielle Vienneau: Methodology, Data curation, Writing - review \& editing. Reto Pieren: Methodology, Data curation, Writing - review \& editing. Medea Imboden: Methodology, Data curation, Writing - review \& editing. Jean-Marc Wunderli: Methodology, Data curation, Writing review \& editing, Funding acquisition. Christian Cajochen: Methodology, Data curation, Writing - review \& editing, Funding acquisition. Mark Brink: Methodology, Data curation, Writing - review \& editing, Funding acquisition. Martin Röösli: Methodology, Data curation, Writing - review \& editing, Funding acquisition. Nicole ProbstHensch: Conceptualization, Methodology, Data curation, Writing - review \& editing, Supervision, Funding acquisition, Project administration.

\section{Declaration of Competing Interest}

The authors declare that they have no known competing financial interests or personal relationships that could have appeared to influence the work reported in this paper.

\section{Acknowledgements}

This work was supported by the Swiss National Science Foundation, SNF-SAPALDIA (grants numbers 33CS30-148470/1, 33CSCO-134276/ 1, 33CSCO-108796, 324730_135673, 3247BO-104283, 3247BO104288, 3247BO-104284, 3247-065896, 3100-059302, 3200-052720, 3200-042532, 4026-028099, PMPDP3_129021/1, PMPDP3_141671/1); SNF-SiRENE (grant number CRSII3_147635)and the Swiss Federal Office for the Environment. SAPALDIA is also supported by the Federal Office of Public Health, the Federal Office of Roads and Transport, the cantonal government of Aargau, Basel-Stadt, Basel-Land, Geneva, Luzern, Ticino, Valais, and Zürich, the Swiss Lung League, the canton's Lung League of Basel Stadt/Basel Landschaft, Geneva, Ticino, Valais, Graubünden and Zurich, Stiftung ehemals Bündner Heilstätten, SUVA, Freiwillige Akademische Gesellschaft, UBS Wealth Foundation, Talecris Biotherapeutics GmbH, Abbott Diagnostics, European Commission 018996 (GABRIEL), Wellcome Trust WT 084703MA.

\section{Appendix A. Supplementary material}

Supplementary data to this article can be found online at https:// doi.org/10.1016/j.envint.2020.106014.

\section{References}

Ackermann-Liebrich, U., Kuna-Dibbert, B., Probst-Hensch, N.M., Schindler, C., Felber Dietrich, D., Stutz, E.Z., Bayer-Oglesby, L., Baum, F., Brandli, O., Brutsche, M., Downs, S.H., Keidel, D., Gerbase, M.W., Imboden, M., Keller, R., Knopfli, B., Kunzli, N., Nicod, L., Pons, M., Staedele, P., Tschopp, J.M., Zellweger, J.P., Leuenberger, P., 2005. Follow-up of the Swiss cohort study on air pollution and lung diseases in adults (SAPALDIA 2) 1991-2003: methods and characterization of participants. Soz. Praventivmed. 50, 245-263.

Antonsen, S., Mok, P.L.H., Webb, R.T., Mortensen, P.B., McGrath, J.J., Agerbo, E., Brandt, J., Geels, C., Christensen, J.H., Pedersen, C.B., 2020. Exposure to air pollution during childhood and risk of developing schizophrenia: a national cohort study. Lancet Planet Health 4, e64-e73.

Babisch, W., 2003. Stress hormones in the research on cardiovascular effects of noise. Noise Health 5, 1-11.

Babisch, W., Pershagen, G., Selander, J., Houthuijs, D., Breugelmans, O., Cadum, E., Vigna-Taglianti, F., Katsouyanni, K., Haralabidis, A.S., Dimakopoulou, K., Sourtzi, P., Floud, S., Hansell, A.L., 2013. Noise annoyance-a modifier of the association between noise level and cardiovascular health? Sci. Total Environ. 452-453, 50-57.

Banay, R.F., James, P., Hart, J.E., Kubzansky, L.D., Spiegelman, D., Okereke, O.I., Spengler, J.D., Laden, F., 2019. Greenness and depression incidence among older women. Environ. Health Perspect. 127, 27001.

Barragán-Mejía, M.G., Castilla-Serna, L., Calderón-Guzmán, D., Hernández-Islas, J.L., Labra-Ruiz, N.A., Rodríguez-Pérez, R.A., Santamaría-Del Angel, D., 2002. Effect of nutritional status and ozone exposure on rat brain serotonin. Arch. Med. Res. 33, 15-19.

Basner, M., 2008. Nocturnal aircraft noise exposure increases objectively assessed daytime sleepiness. Somnologie 12, 110-117.

Baudin, C., Lefèvre, M., Champelovier, P., Lambert, J., Laumon, B., Evrard, A.-S., 2018. Aircraft noise and psychological ill-health: the results of a cross-sectional study in France. Int. J. Environ. Res. Public Health 15, 1642.

Beutel, M.E., Junger, C., Klein, E.M., Wild, P., Lackner, K., Blettner, M., Binder, H., Michal, M., Wiltink, J., Brahler, E., Munzel, T., 2016. Noise annoyance is associated with depression and anxiety in the general population- the contribution of aircraft noise. PLoS ONE 11 e0155357.

Black, P.H., Garbutt, L.D., 2002. Stress, inflammation and cardiovascular disease. J. Psychosom. Res. 52, 1-23.

Bos, I., Jacobs, L., Nawrot, T., De Geus, B., Torfs, R., Panis, L.I., Degraeuwe, B., Meeusen, R., 2011. No exercise-induced increase in serum BDNF after cycling near a major traffic road. Neurosci. Lett. 500, 129-132.

Bostwick, J.M., Pankratz, V.S., 2000. Affective disorders and suicide risk: a reexamination. Am. J. Psychiatry 157, 1925-1932.

Bratman, G.N., Anderson, C.B., Berman, M.G., Cochran, B., De Vries, S., Flanders, J., Folke, C., Frumkin, H., Gross, J.J., Hartig, T., 2019. Nature and mental health: an ecosystem service perspective. Sci. Adv. 5 eaax0903.

Briley, M., Moret, C., 2010. Improvement of social adaptation in depression with serotonin and norepinephrine reuptake inhibitors. Neuropsychiatr. Dis. Treat. 6, 647-655.

Brink, M., Schäffer, B., Vienneau, D., Foraster, M., Pieren, R., Eze, I.C., Cajochen, C., Probst-Hensch, N., Röösli, M., Wunderli, J.M., 2019. A survey on exposure-response relationships for road, rail, and aircraft noise annoyance: Differences between continuous and intermittent noise. Environ. Int. 125, 277-290.

Bross, I.D., 1971. Critical levels, statistical language and scientific inference. Found Stat Inference 500-513.

Bus, B., Molendijk, M., Tendolkar, I., Penninx, B., Prickaerts, J., Elzinga, B., Voshaar, R. 2015. Chronic depression is associated with a pronounced decrease in serum brainderived neurotrophic factor over time. Mol. Psychiatry 20, 602.

Cancino, A., Leiva-Bianchi, M., Serrano, C., Ballesteros-Teuber, S., Cáceres, C., Vitriol, V., 2018. Factors associated with psychiatric comorbidity in depression patients in primary health care in Chile. Depress Res. Treat 2018, 1701978.

Cattaneo, A., Cattane, N., Begni, V., Pariante, C.M., Riva, M.A., 2016. The human BDNF gene: peripheral gene expression and protein levels as biomarkers for psychiatric disorders. Transl. Psychiatry 6, e958.

Clark, C., Paunovic, K., 2018. WHO Environmental noise guidelines for the European Region: A systematic review on environmental noise and quality of life, wellbeing and mental health. Int. J. Environ. Res. Public Health 15, 2400.

Crawford, Bethany, Craig, Zoe, Mansell, Georgina, White, Isobel, Smith, Adam, Spaull, Steve, Imm, Jennifer, Hannon, Eilis, Wood, Andrew, Yaghootkar, Hanieh, Ji, Yingjie, Mullins, Niamh, Lewis, Cathryn M, Mill, Jonathan, Murphy, Therese M, 2018. DNA methylation and inflammation marker profiles associated with a history of depression. Hum. Mol. Genet. 27 (16), 2840-2850. https://doi.org/10.1093/hmg/ddy199.

Crouse, Dan L., Peters, Paul A., Hystad, Perry, Brook, Jeffrey R., van Donkelaar, Aaron, Martin, Randall V., Villeneuve, Paul J., Jerrett, Michael, Goldberg, Mark S., Pope III, C. Arden, Brauer, Michael, Brook, Robert D., Robichaud, Alain, Menard, Richard, Burnett, Richard T., 2015. Ambient PM 2.5 , O 3 , and NO 2 exposures and associations with mortality over 16 years of follow-up in the canadian census health and environment cohort (CanCHEC). Environ. Health Perspect. 123 (11), 1180-1186. https://doi.org/10.1289/ehp.1409276.

Dorado-Martínez, C., Paredes-carbajal, C., Mascher, D., Borgonio-Pérez, G., Rivas-arancibia, S., 2001. Effects of different ozone doses on memory, motor activity and lipid peroxidation levels, in rats. Int. J. Neurosci. 108, 149-161.

Dratva, J., Zemp, E., Felber Dietrich, D., Bridevaux, P.O., Rochat, T., Schindler, C., Gerbase, M.W., 2010. Impact of road traffic noise annoyance on health-related quality of life: results from a population-based study. Qual. Life Res. 19, 37-46.

Dreger, S., Schüle, S.A., Hilz, L.K., Bolte, G., 2019. Social inequalities in environmental 
noise exposure: a review of evidence in the WHO European region. Int. J. Environ. Res. Public Health 16.

Druss, B.G., Hwang, I., Petukhova, M., Sampson, N.A., Wang, P.S., Kessler, R.C., 2009. Impairment in role functioning in mental and chronic medical disorders in the United States: results from the National Comorbidity Survey Replication. Mol. Psychiatry 14, 728-737.

Dzhambov, A., Tilov, B., Markevych, I., Dimitrova, D.J., 2017. Residential road traffic noise and general mental health in youth: the role of noise annoyance, neighborhood restorative quality, physical activity, and social cohesion as potential mediators. Environ. Int. 109, 1-9.

Dzhambov, A.M., Lercher, P., 2019. Road traffic noise exposure and depression/anxiety: an updated systematic review and meta-analysis. Int. J. Environ. Res. Public Health $16,4134$.

Dzhambov, A.M., Markevych, I., Tilov, B., Arabadzhiev, Z., Stoyanov, D., Gatseva, P., Dimitrova, D.D., 2018. Pathways linking residential noise and air pollution to mental ill-health in young adults. Environ. Res. 166, 458-465.

Eze, I.C., Foraster, M., Schaffner, E., Vienneau, D., Héritier, H., Pieren, R., Thiesse, L., Rudzik, F., Rothe, T., Pons, M., 2018. Transportation noise exposure, noise annoyance and respiratory health in adults: A repeated-measures study. Environ. Int. 121, 741-750.

Eze, I.C., Foraster, M., Schaffner, E., Vienneau, D., Heritier, H., Rudzik, F., Thiesse, L., Pieren, R., Imboden, M., von Eckardstein, A., Schindler, C., Brink, M., Cajochen, C., Wunderli, J.M., Roosli, M., Probst-Hensch, N., 2017a. Long-term exposure to transportation noise and air pollution in relation to incident diabetes in the SAPALDIA study. Int. J. Epidemiol. 46, 1115-1125.

Eze, I.C., Imboden, M., Foraster, M., Schaffner, E., Kumar, A., Vienneau, D., Heritier, H., Rudzik, F., Thiesse, L., Pieren, R., von Eckardstein, A., Schindler, C., Brink, M., Wunderli, J.M., Cajochen, C., Roosli, M., Probst-Hensch, N., 2017b. Exposure to night-time traffic noise, melatonin-regulating gene variants and change in glycemia in adults. Int. J. Environ. Res. Public Health 14.

Eze, I.C., Jeong, A., Schaffner, E., Rezwan, F.I., Ghantous, A., Foraster, M., Vienneau, D., Kronenberg, F., Herceg, Z., Vineis, P., Brink, M., Wunderli, J.-M., Schindler, C., Cajochen, C., Röösli, M., Holloway, J.W., Imboden, M., Probst-Hensch, N., 2020. Genome-wide DNA methylation in peripheral blood and long-term exposure to source-specific transportation noise and air pollution: the SAPALDIA study. Environ. Health Perspect. 128067003.

Fan, S.-J., Heinrich, J., Bloom, M.S., Zhao, T.-Y., Shi, T.-X., Feng, W.-R., Sun, Y., Shen, J.C., Yang, Z.-C., Yang, B.-Y., Dong, G.-H., 2020. Ambient air pollution and depression: A systematic review with meta-analysis up to 2019. Sci. Total Environ. 701134721.

Fields, J., De Jong, R., Gjestland, T., Flindell, I., Job, R., Kurra, S., Lercher, P., Vallet, M., Yano, T., UNIVERSITY, R.T.A.R., 2001. Standardized general-purpose noise reaction questions for community noise surveys: Research and a recommendation. J. Sound Vib. 242, 641-679.

Floud, S., Vigna-Taglianti, F., Hansell, A., Blangiardo, M., Houthuijs, D., Breugelmans, O., Cadum, E., Babisch, W., Selander, J., Pershagen, G., 2011. Medication use in relation to noise from aircraft and road traffic in six European countries: results of the HYENA study. Occup. Environ. Med. 68, 518-524.

Fluharty, M., Taylor, A.E., Grabski, M., Munafò, M.R., 2017. The association of cigarette smoking with depression and anxiety: a systematic review. Nicotine Tob. Res. 19, $3-13$.

Foraster, M., Eze, I.C., Schaffner, E., Vienneau, D., Heritier, H., Endes, S., Rudzik, F., Thiesse, L., Pieren, R., Schindler, C., Schmidt-Trucksass, A., Brink, M., Cajochen, C., Marc Wunderli, J., Roosli, M., Probst-Hensch, N., 2017. Exposure to road, railway, and aircraft noise and arterial stiffness in the SAPALDIA study: annual average noise levels and temporal noise characteristics. Environ. Health Perspect. 125097004.

Foraster, M., Eze, I.C., Vienneau, D., Brink, M., Cajochen, C., Caviezel, S., Heritier, H., Schaffner, E., Schindler, C., Wanner, M., Wunderli, J.M., Roosli, M., Probst-Hensch, N., 2016. Long-term transportation noise annoyance is associated with subsequent lower levels of physical activity. Environ. Int. 91, 341-349.

Foraster, M., Eze, I.C., Vienneau, D., Schaffner, E., Jeong, A., Heritier, H., Rudzik, F., Thiesse, L., Pieren, R., Brink, M., Cajochen, C., Wunderli, J.M., Roosli, M., ProbstHensch, N., 2018. Long-term exposure to transportation noise and its association with adiposity markers and development of obesity. Environ. Int. 121, 879-889.

Franzen, P.L., Buysse, D.J., 2008. Sleep disturbances and depression: risk relationships for subsequent depression and therapeutic implications. Dialogues Clin. Neurosci. 10, 473-481.

Fyhri, A., Klæboe, R., 2009. Road traffic noise, sensitivity, annoyance and self-reported health-A structural equation model exercise. Environ. Int. 35, 91-97.

Gea, A., Beunza, J.J., Estruch, R., Sánchez-Villegas, A., Salas-Salvadó, J., Buil-Cosiales, P., Gómez-Gracia, E., Covas, M.I., Corella, D., Fiol, M., Arós, F., Lapetra, J., LamuelaRaventós, R.M., Wärnberg, J., Pintó, X., Serra-Majem, L., Martínez-González, M.A., 2013. Alcohol intake, wine consumption and the development of depression: the PREDIMED study. BMC Med. 11, 192.

Gianfredi, V., Blandi, L., Cacitti, S., Minelli, M., Signorelli, C., Amerio, A., Odone, A., 2020. Depression and objectively measured physical activity: a systematic review and meta-analysis. Int. J. Environ. Res. Public Health 2020;17.

González-Piña, R., Paz, C., 1997. Brain monoamine changes in rats after short periods of ozone exposure. Neurochem. Res. 22, 63-66.

Guo, L., Li, P.H., Li, H., Colicino, E., Colicino, S., Wen, Y., Zhang, R., Feng, X., Barrow, T.M., Cayir, A., Baccarelli, A.A., Byun, H.M., 2017. Effects of environmental noise exposure on DNA methylation in the brain and metabolic health. Environ. Res. 153, $73-82$.

Halperin, D., 2014. Environmental noise and sleep disturbances: A threat to health? Sleep Sci. 7, 209-212.

Hammersen, F., Niemann, H., Hoebel, J., 2016. Environmental noise annoyance and mental health in adults: findings from the cross-sectional german health update
(GEDA) study 2012. Int. J. Environ. Res. Public Health 13.

Hardeveld, F., Spijker, J., De Graaf, R., Nolen, W.A., Beekman, A.T., 2010. Prevalence and predictors of recurrence of major depressive disorder in the adult population. Acta Psychiatr. Scand. 122, 184-191.

He, S., Smargiassi, A., Low, N., Bilodeau-Bertrand, M., Ayoub, A., Auger, N., 2019. Residential noise exposure and the longitudinal risk of hospitalization for depression after pregnancy: Postpartum and beyond. Environ. Res. 170, 26-32.

Heritier, H., Vienneau, D., Foraster, M., Eze, I.C., Schaffner, E., Thiesse, L., Rudzik, F. Habermacher, M., Kopfli, M., Pieren, R., Brink, M., Cajochen, C., Wunderli, J.M., Probst-Hensch, N., Roosli, M., 2017. Transportation noise exposure and cardiovascular mortality: a nationwide cohort study from Switzerland. Eur. J. Epidemiol. 32, $307-315$.

Hiramatsu, K., Yamamoto, T., Taira, K., Ito, A., Nakasone, T., 1997. A survey on health effects due to aircraft noise on residents living around Kadena air base in the Ryukyus. J. Sound Vib. 205, 451-460.

Huang, C.-Q., Dong, B.-R., Lu, Z.-C., Yue, J.-R., Liu, Q.-X., 2010. Chronic diseases and risk for depression in old age: a meta-analysis of published literature. Ageing Res. Rev. 9, $131-141$.

Huber, C., 2013. Generalized structural equation modeling using stata. Italian Stata Users' Group Meetings 2013 06, Stata Users Group.

Hyde, J.S., Mezulis, A.H., 2020. Gender differences in depression: biological, affective, cognitive, and sociocultural factors. Harv. Rev. Psychiatry 28, 4-13.

Jaussent, I., Bouyer, J., Ancelin, M.L., Akbaraly, T., Pérès, K., Ritchie, K., Besset, A., Dauvilliers, Y., 2011. Insomnia and daytime sleepiness are risk factors for depressive symptoms in the elderly. Sleep 34, 1103-1110.

Jensen, H.A., Rasmussen, B., Ekholm, O., 2018. Neighbour and traffic noise annoyance: a nationwide study of associated mental health and perceived stress. Eur. J. Public Health 28, 1050-1055.

Johns, M.W., 1991. A new method for measuring daytime sleepiness: the Epworth sleepiness scale. Sleep 14, 540-545.

Judd, L.L., Akiskal, H.S., Zeller, P.J., Paulus, M., Leon, A.C., Maser, J.D., Endicott, J., Coryell, W., Kunovac, J.L., Mueller, T.I., Rice, J.P., Keller, M.B., 2000. Psychosocial disability during the long-term course of unipolar major depressive disorder. Arch. Gen. Psychiatry 57, 375-380.

Karipidis, I., Vienneau, D., Habermacher, M., Köpflii, M., Brink, M., Probst-Hensch, N., Röösli, M., Wunderli, J.-M., 2014. Reconstruction of historical noise exposure data for environmental epidemiology in Switzerland within the SiRENE project. Noise Mapping 1.

Keller, J., Gomez, R., Williams, G., Lembke, A., Lazzeroni, L., Murphy Jr., G.M., Schatzberg, A.F., 2017. HPA axis in major depression: cortisol, clinical symptomatology and genetic variation predict cognition. Mol. Psychiatry 22, 527-536.

Kiely, K.M., Butterworth, P., 2015. Validation of four measures of mental health against depression and generalized anxiety in a community based sample. Psychiatry Res. 225, 291-298.

Kishikawa, H., Matsui, T., Uchiyama, I., Miyakawa, M., Hiramatsu, K., Stansfeld, S.A., 2009. Noise sensitivity and subjective health: Questionnaire study conducted along trunk roads in Kusatsu, Japan. Noise Health 11, 111.

Klompmaker, J.O., Hoek, G., Bloemsma, L.D., Wijga, A.H., van den Brink, C., Brunekreef, B., Lebret, E., Gehring, U., Janssen, N.A., 2019. Associations of combined exposures to surrounding green, air pollution and traffic noise on mental health. Environ. Int. $129,525-537$.

Krefis, A.C., Albrecht, M., Kis, A., Langenbruch, A., Augustin, M., Augustin, J., 2017. Multivariate analysis of noise, socioeconomic and sociodemographic factors and their association with depression on borough level in the city state of Hamburg, Germany. J. Depression Therapy 1,1 .

Kroesen, M., Stallen, P.J.M., Molin, E.J., Miedema, H.M., Vos, H., Janssen, S.A., van Wee, B., 2008. Assessing the role of mediators in the noise-health relationship via structural equation analysis. 9th International Congress on Noise as a Public Health Problem Foxwoods. CT: ICBEN.

Leijssen, J.B., Snijder, M.B., Timmermans, E.J., Generaal, E., Stronks, K., Kunst, A.E., 2019. The association between road traffic noise and depressed mood among different ethnic and socioeconomic groups. The HELIUS study. Int. J. Hyg. Environ. Health 222, 221-229.

Lépine, J.P., Briley, M., 2011. The increasing burden of depression. Neuropsychiatr. Dis. Treat. 7, 3-7.

Liu, L.-J.S., Tsai, M.-Y., Keidel, D., Gemperli, A., Ineichen, A., Hazenkamp-von Arx, M., Bayer-Oglesby, L., Rochat, T., Künzli, N., Ackermann-Liebrich, U., 2012. Long-term exposure models for traffic related NO2 across geographically diverse areas over separate years. Atmos. Environ. 46, 460-471.

Lund, C., Brooke-Sumner, C., Baingana, F., Baron, E.C., Breuer, E., Chandra, P., Haushofer, J., Herrman, H., Jordans, M., Kieling, C., Medina-Mora, M.E., Morgan, E., Omigbodun, O., Tol, W., Patel, V., Saxena, S., 2018. Social determinants of mental disorders and the Sustainable Development Goals: a systematic review of reviews. Lancet Psychiatry 5, 357-369.

Luppino, F.S., de Wit, L.M., Bouvy, P.F., Stijnen, T., Cuijpers, P., Penninx, B.W.J.H., Zitman, F.G., 2010. Overweight, obesity, and depression: a systematic review and meta-analysis of longitudinal studies. Arch. Gen. Psychiatry 67, 220-229.

Martens, A.L., Reedijk, M., Smid, T., Huss, A., Timmermans, D., Strak, M., Swart, W., Lenters, V., Kromhout, H., Verheij, R., 2018. Modeled and perceived RF-EMF, noise and air pollution and symptoms in a population cohort. Is perception key in predicting symptoms? Sci. Total Environ. 639, 75-83.

Martin, B.W., Ackermann-Liebrich, U., Leuenberger, P., Kunzli, N., Stutz, E.Z., Keller, R., Zellweger, J.P., Wuthrich, B., Monn, C., Blaser, K., Bolognini, G., Bongard, J.P., Brandli, O., Braun, P., Defila, C., Domenighetti, G., Grize, L., Karrer, W., KellerWossidlo, H., Medici, T.C., Peeters, A., Perruchoud, A.P., Schindler, C., Schoeni, M.H., Villiger, B., et al., 1997. SAPALDIA: methods and participation in the cross- 
sectional part of the Swiss study on air pollution and lung diseases in adults. Soz. Praventivmed. 42, 67-84.

Meng, Z., Qin, G., Zhang, B., Geng, H., Bai, Q., Bai, W., Liu, C., 2003. Oxidative damage of sulfur dioxide inhalation on lungs and hearts of mice. Environ. Res. 93, 285-292.

Moylan, S., Eyre, H.A., Maes, M., Baune, B.T., Jacka, F.N., Berk, M., 2013. Exercising the worry away: how inflammation, oxidative and nitrogen stress mediates the beneficial effect of physical activity on anxiety disorder symptoms and behaviours. Neurosci. Biobehav. Rev. 37, 573-584.

Mullington, J.M., Simpson, N.S., Meier-Ewert, H.K., Haack, M., 2010. Sleep loss and inflammation. Best Pract. Res. Clin. Endocrinol. Metab. 24, 775-784.

Münzel, T., Daiber, A., Steven, S., Tran, L.P., Ullmann, E., Kossmann, S., Schmidt, F.P., Oelze, M., Xia, N., Li, H., 2017. Effects of noise on vascular function, oxidative stress, and inflammation: mechanistic insight from studies in mice. Eur. Heart J. 38, $2838-2849$.

Okokon, E.O., Yli-Tuomi, T., Turunen, A.W., Tiittanen, P., Juutilainen, J., Lanki, T., 2018. Traffic noise, noise annoyance and psychotropic medication use. Environ. Int. 119, 287-294.

Orban, E., McDonald, K., Sutcliffe, R., Hoffmann, B., Fuks, K.B., Dragano, N., Viehmann, A., Erbel, R., Jöckel, K.-H., Pundt, N., 2015. Residential road traffic noise and high depressive symptoms after five years of follow-up: results from the Heinz Nixdorf recall study. Environ. Health Perspect. 124, 578-585.

Osby, U., Brandt, L., Correia, N., Ekbom, A., Sparen, P., 2001. Excess mortality in bipolar and unipolar disorder in Sweden. Arch. Gen. Psychiatry 58, 844-850.

Panczak, R., Galobardes, B., Voorpostel, M., Spoerri, A., Zwahlen, M., Egger, M., 2012. A Swiss neighbourhood index of socioeconomic position: development and association with mortality. J. Epidemiol. Community Health 66, 1129-1136.

Park, J., Chung, S., Lee, J., Sung, J.H., Cho, S.W., Sim, C.S., 2017. Noise sensitivity, rather than noise level, predicts the non-auditory effects of noise in community samples: a population-based survey. BMC Public Health 17, 315.

Pearl, J., Glymour, M., Jewell, N.P., 2016. Causal Inference in Statistics: A Primer. John Wiley \& Sons ISBN: 978-1-119-18684-7.

Persson-Waye, K., Bengtsson, J., Rylander, R., Hucklebridge, F., Evans, P., Clow, A., 2002. Low frequency noise enhances cortisol among noise sensitive subjects during work performance. Life Sci. 70, 745-758.

Pyko, A., Andersson, N., Eriksson, C., de Faire, U., Lind, T., Mitkovskaya, N., Ogren, M., Ostenson, C.G., Pedersen, N.L., Rizzuto, D., Wallas, A.K., Pershagen, G., 2019. Longterm transportation noise exposure and incidence of ischaemic heart disease and stroke: a cohort study. Occup. Environ. Med. 76, 201-207.

Pyko, A., Eriksson, C., Lind, T., Mitkovskaya, N., Wallas, A., Ögren, M., Östenson, C.G., Pershagen, G., 2017. Long-term exposure to transportation noise in relation to development of obesity - a cohort study. Environ. Health Perspect. 125117005.

Raison, C.L., Capuron, L., Miller, A.H., 2006. Cytokines sing the blues: inflammation and the pathogenesis of depression. Trends Immunol. 27, 24-31.

Roberts Jr, J.D., Chiche, J.-D., Kolpa, E.M., Bloch, D.B., Bloch, K.D., Physiology, M., 2007. cGMP-dependent protein kinase I interacts with TRIM39R, a novel Rpp21 domaincontaining TRIM protein. Am. J. Physiol. Lung Cell. Mol. Physiol. 293, L903-L912.

Rocha, K., Perez, K., Rodriguez-Sanz, M., Obiols, J.E., Borrell, C., 2012. Perception of environmental problems and common mental disorders (CMD). Soc. Psychiatry Psychiatr. Epidemiol. 47, 1675-1684.

Röösli, M., Vienneau, D., Foraster, M., Eze, I.C., Héritier, H., Schaffner, E., Thiesse, L., Rudzik, F., Pieren, R., Habermacher, M., 2017. Short and long term effects of transportation noise exposure (SiRENE): an interdisciplinary approach. In: Proceedings of the 12th ICBEN Congress on Noise as a Public Health Problem, Zurich.

Rotermann, M., 2007. Marital breakdown and subsequent depression. Health Rep. 18, 33-44.

Saghafian, F., Malmir, H., Saneei, P., Milajerdi, A., Larijani, B., Esmaillzadeh, A., 2018. Fruit and vegetable consumption and risk of depression: accumulative evidence from an updated systematic review and meta-analysis of epidemiological studies. Br. J. Nutr. 119, 1087-1101.

Schlatter, F., Piquerez, A., Habermacher, M., Ragettli, M., Röösli, M., Brink, M., Cajochen, C., Probst-Hensch, N., Foraster, M., Wunderli, J.-M., 2017. Validation of large scale noise exposure modelling by long-term measurements. Noise Mapping 4, 75-86.

Schreckenberg, D., Griefahn, B., Meis, M., 2010. The associations between noise sensitivity, reported physical and mental health, perceived environmental quality, and noise annoyance. Noise Health 12, 7-16.

Seidler, A., Hegewald, J., Seidler, A.L., Schubert, M., Wagner, M., Dröge, P., Haufe, E., Schmitt, J., Swart, E., Zeeb, H., 2017. Association between aircraft, road and railway traffic noise and depression in a large case-control study based on secondary data. Environ. Res. 152, 263-271.

Silveira, E., Taft, C., Sundh, V., Waern, M., Palsson, S., Steen, B., 2005. Performance of the SF-36 health survey in screening for depressive and anxiety disorders in an elderly female Swedish population. Qual. Life Res. 14, 1263-1274.

Slavich, G.M., Irwin, M.R., 2014. From stress to inflammation and major depressive disorder: a social signal transduction theory of depression. Psychol. Bull. 140, 774.

Stansfeld, S., Gallacher, J., Babisch, W., Shipley, M., 1996. Road traffic noise and psychiatric disorder: prospective findings from the caerphilly study. BMJ 313, 266-267.

Stansfeld, S., Shipley, M., 2015. Noise sensitivity and future risk of illness and mortality. Sci. Total Environ. 520, 114-119.

Stansfeld, S.A., 1992. Noise, noise sensitivity and psychiatric disorder: epidemiological and psychophysiological studies. Psychol. Med. 22 (Suppl), 1-44.

Sygna, K., Aasvang, G.M., Aamodt, G., Oftedal, B., Krog, N.H., 2014. Road traffic noise, sleep and mental health. Environ. Res. 131, 17-24.

Tarnopolsky, A., Watkins, G., Hand, D.J., 1980. Aircraft noise and mental health: I. Prevalence of individual symptoms. Psychol. Med. 10, 683-698.

Tsuno, N., Besset, A., Ritchie, K., 2005. Sleep and depression. J. Clin. Psychiatry 66, 1254-1269.

Tyrrell, J., Mulugeta, A., Wood, A.R., Zhou, A., Beaumont, R.N., Tuke, M.A., Jones, S.E., Ruth, K.S., Yaghootkar, H., Sharp, S., 2019. Using genetics to understand the causal influence of higher BMI on depression. Int. J. Epidemiol. 48, 834-848.

van den Bosch, M., Meyer-Lindenberg, A., 2019. Environmental exposures and depression: biological mechanisms and epidemiological evidence. Annu. Rev. Public Health 40, 239-259.

van Kamp, I., van Kempen, E., Baliatsas, C., Houthuijs, D., 2013. Mental health as context rather than health outcome of noise: competing hypotheses regarding the role of sensitivity, perceived soundscapes and restoration. Proceedings of the 42nd International Congress and Exposition on Noise Control Engineering.

Vienneau, D., de Hoogh, K., Faeh, D., Kaufmann, M., Wunderli, J.M., Röösli, M., 2017. More than clean air and tranquillity: Residential green is independently associated with decreasing mortality. Environ. Int. 108, 176-184.

Voinov, B., Richie, W.D., Bailey, R.K., 2013. Depression and chronic diseases: it is time for a synergistic mental health and primary care approach. Prim Care Companion CNS Disord 15.

von Lindern, E., Hartig, T., Lercher, P., 2016. Traffic-related exposures, constrained restoration, and health in the residential context. Health Place 39, 92-100.

Vos, T., Allen, C., Arora, M., Barber, R.M., Bhutta, Z.A., Brown, A., Carter, A., Casey, D.C., Charlson, F.J., Chen, A.Z., 2016. Global, regional, and national incidence, prevalence, and years lived with disability for 310 diseases and injuries, 1990-2015: a systematic analysis for the Global Burden of Disease Study 2015. Lancet 388, 1545-1602.

Ware, J.E., Kosinski, M., 2001. SF-36 physical \& mental health summary scales: a manual for users of version 1. Quality Metric Inc., Montreal, QC, Canada.

Weissman, M.M., Wickramaratne, P., Nomura, Y., Warner, V., Verdeli, H., Pilowsky, D.J., Grillon, C., Bruder, G., 2005. Families at high and low risk for depression: a 3-generation study. Arch. Gen. Psychiatry 62, 29-36.

WHO, 2011. Burden of disease from environmental noise: Quantification of healthy life years lost in Europe. Copenhagen, Denmark: World Health Organization. Regional Office for Europe.

WHO, 2017. Depression and other common mental disorders: global health estimates. World Health Organization: Geneva, Switzerland. https://apps.who.int/iris/bitstream/handle/10665/254610/WHOMSD? sequence = 1 (Accessed 05 June 2019).

Wothge, J., Belke, C., Möhler, U., Guski, R., Schreckenberg, D., 2017. The combined effects of aircraft and road traffic noise and aircraft and railway noise on noise annoyance-an analysis in the context of the joint research initiative NORAH. Int. J. Environ. Res. Public Health 14.

Wright, D.M., Newell, K., Maguire, A., O’Reilly, D., 2018. Aircraft noise and self-assessed mental health around a regional urban airport: a population based record linkage study. Environ. Health 17, 74.

Yoon, J.-H., Won, J.-U., Lee, W., Jung, P.K., Roh, J., 2014. Occupational noise annoyance linked to depressive symptoms and suicidal ideation: a result from nationwide survey of Korea. PLoS ONE 9 e105321.

Yoshida, T., Osada, Y., Kawaguchi, T., Hoshiyama, Y., Yoshida, K., Yamamoto, K., 1997. Effects of road traffic noise on inhabitants of Tokyo. J. Sound Vib. 205, 517-522.

Zhang, L., Mei, Y., Fu, N.-Y., Guan, L., Xie, W., Liu, H.-H., Yu, C.-D., Yin, Z., Victor, C.Y., You, H., 2012. TRIM39 regulates cell cycle progression and DNA damage responses via stabilizing p21. Proc. Natl. Acad. Sci. U. S. A. 109, 20937-20942.

Zhao, X., Lynch Jr, J.G., Chen, Q.J., 2010. Reconsidering Baron and Kenny: Myths and truths about mediation analysis. J. Consum. Res. 37, 197-206.

Zhu, Y., Strachan, E., Fowler, E., Bacus, T., Roy-Byrne, P., Zhao, J., 2019. Genome-wide profiling of DNA methylome and transcriptome in peripheral blood monocytes for major depression: A Monozygotic Discordant Twin Study. Transl. Psychiatry 9, 215.

Zou, G., 2004. A modified poisson regression approach to prospective studies with binary data. Am. J. Epidemiol. 159, 702-706. 